\title{
Shopping Externalities and Self-Fulfilling Unemployment Fluctuations
}

\section{Greg Kaplan}

Princeton University and National Bureau of Economic Research

\section{Guido Menzio}

University of Pennsylvania and National Bureau of Economic Research

\begin{abstract}
We propose a theory of self-fulfilling unemployment fluctuations. When a firm increases its workforce, it raises demand and weakens competition facing other firms, as employed workers spend more and have less time to search for low prices than unemployed workers. These effects induce other firms to hire more labor in order to scale up their presence in the product market. The feedback between employment and product market conditions generates multiple equilibria-and the possibility of self-fulfilling fluctuations - if differences in shopping behavior between employed and unemployed are large enough. Evidence on spending, shopping, and prices suggests that this is the case.
\end{abstract}

\section{Introduction}

We propose a novel theory of self-fulfilling unemployment fluctuations. When a firm increases its workforce, it increases the demand facing other firms - as workers have more income to spend when employed than when unemployed-and it decreases the extent of competition fac-

We thank the Kielts-Nielsen Data Center at the University of Chicago Booth School of Business for providing access to the Kielts-Nielsen Consumer Panel Dataset. We thank the editor, Harald Uhlig, and three anonymous referees for insightful and detailed suggestions that helped us revise the paper. We are also grateful to Mark Aguiar, Jim Albrecht, Michele Boldrin, Russ Cooper, Ben Eden, Chris Edmond, Roger Farmer, Veronica Guer-

Electronically published May 3, 2016

[ Journal of Political Economy, 2016, vol. 124, no. 3]

(C) 2016 by The University of Chicago. All rights reserved. 0022-3808/2016/12403-0002\$10.00 
ing other firms - as workers have less time to search for low prices when employed than when unemployed. In turn, the increase in demand and the decline in competition induce other firms to hire more labor in order to enter or scale up their presence in the product market. The feedback loop between unemployment and the conditions of the product market can lead to multiple equilibria. If firms expect higher unemployment, they demand less labor, they create fewer vacancies, and higher unemployment materializes. If firms expect lower unemployment, they demand more labor, they create more vacancies, and lower unemployment materializes. Thus, economic fluctuations can be caused not only by changes in fundamentals but also by self-fulfilling changes in the agents' expectations about unemployment.

The theory is motivated by the observation that unemployed and employed people behave differently in the product market. First, unemployed people spend more time shopping. Using the American Time Use Survey and other time use surveys, Krueger and Muller (2010) find that unemployed people spend between 15 and 30 percent more time shopping than employed people. Second, unemployed people pay lower prices. Using the Kielts-Nielsen Consumer Panel Data, Kaplan and Menzio (2015) find that households in which at least one head is nonemployed pay between 1 and 4 percent less for the same goods than households in which all heads are employed. Third, unemployed people spend less. Using the Panel Study of Income Dynamics, Stephens (2001) finds that households reduce their food expenditures by approximately 15 percent after becoming unemployed.

We use search theory to build a model economy that captures the above differences in shopping behavior between employed and unemployed people. We model the labor market as in Mortensen and Pissarides (1994). In this market, unemployed workers and vacant jobs come together through a frictional matching process. In equilibrium, there is unemployment because it takes time for a worker to find a viable job. Moreover, there is an income differential between employed and unemployed workers, because employed workers can extract a fraction of the surplus that they create when matched with a firm. We model the product market as in Burdett and Judd (1983). In this market, sellers (i.e., firm-worker pairs) post prices and buyers (i.e., workers) search for sellers with an intensity that depends on their employment status. In equilibrium, sellers post different prices for identical goods. Sellers who post relatively high prices enjoy a higher margin per unit of output

rieri, Bob Hall, Erik Hurst, Martin Schneider, Venky Venkateswaran, Susan Vroman, Steve Williamson, and Randy Wright for many useful comments. Data are provided as supplementary material online. 
sold but they sell fewer units, as they trade only with buyers who did not find any other seller. Sellers who post relatively low prices enjoy a lower margin but they sell more units, as they also trade with buyers who found other sellers. Moreover, since unemployed buyers search more than employed buyers, they pay, on average, lower prices.

We first carry out a theoretical analysis of the model. We find that the model admits multiple steady states if employed buyers have a sufficiently high income relative to unemployed buyers or if employed buyers spend a sufficiently small amount of time searching for low prices relative to unemployed buyers. The result is easy to understand. When a firm decides to increases its workforce, it creates external effects on other firms. On the one hand, by increasing its workforce, the firm tightens the labor market, and as a result, it makes it costlier for other firms to hire additional workers. We refer to this effect as the congestion externality. On the other hand, by increasing its workforce, the firm tilts the composition of buyers in the product market toward types (i.e., employed buyers) who have higher income - and, hence, spend more - and who have less time for shopping - and, hence, are more likely to pay high prices. As a result, the firm makes it more profitable for other firms to hire additional workers to scale up their presence in the product market. We refer to the effect of employment at one firm on other firms' demand as the demand externality, to the effect on other firms' probability of selling at high prices as the market power externality, and to the combination of the two effects as the shopping externalities. If the difference in either income or search intensity between employed and unemployed buyers is sufficiently large, the shopping externalities dominate the congestion externality and the employment decisions of different firms become strategic complements. When this happens, multiple steady states obtain.

When the model admits multiple steady states, we find that it also has multiple equilibria. Different equilibria are associated with different expectations that the agents have about future unemployment. Yet, in each equilibrium, the agents' expectations about future unemployment are correct, in the sense that the path of unemployment that materializes is exactly the one expected by the agent. The existence of multiple equilibria implies that the behavior of our model economy is determined not only by fundamentals (e.g., technology, preferences, and policy) but also by the agents' expectations about future endogenous outcomes. Moreover, we find that some of the equilibria converge to different steady states. This implies that the agents' expectations about future unemployment can be so important as to affect the long-run outcomes of the economy.

We then carry out a quantitative analysis of the model. We calibrate the parameters of the model so as to match the difference in expenditures, shopping time, and prices paid between employed and unem- 
ployed workers, as well as the frequency with which individual workers transition between the states of employment and unemployment. The calibrated model has three steady states - two with some economic activity and one without trade - and, for any initial condition, it has equilibria converging to each of the three steady states. The calibrated model has multiple equilibria because the empirical differences in expenditure and shopping time between employed and unemployed buyers are large enough for the shopping externalities to dominate the congestion externality and, hence, for the employment decisions of different firms to be strategic complements. Interestingly, the market power externality is quantitatively the most important of the shopping externalities. The demand externality is proportional to 15 percent of the expenditures of unemployed buyers, which is the empirical difference in expenditures between employed and unemployed buyers. The market power externality is proportional to 30 percent of the expenditures of unemployed buyers, a magnitude implied by the empirical difference in shopping time between employed and unemployed buyers.

We use the calibrated model to measure the effect of a negative shock to the agents' expectations about the long run. Formally, we model these expectation shocks as a two-state Markov switching process. In what we call the optimistic state, agents expect the economy to converge to the steady state with the lowest unemployment rate. In the pessimistic state, agents expect the economy to converge to the steady state with the intermediate unemployment rate. We then examine the response of the economy to a switch from the optimistic to the pessimistic state. We find that the unemployment rate increases from 5 percent to 10 percent and then slowly declines toward 9 percent, which is the rate associated with the pessimistic steady state. The equity value of a firm falls by approximately 30 percent, and its decline precedes the increase in unemployment. Finally, the increase in unemployment and the decline in the equity value of firms take place without any concurrent decline in real labor productivity. We show that the response of the economy to a negative shock to long-run expectations is similar to the behavior of the US economy during the Great Recession and its aftermath. These findings suggest the possibility that the financial crises that caused the Great Recession might have been amplified and protracted by coordinating the agents' expectations toward a steady state with higher unemployment.

Related literature.-Our contribution is to advance a novel and quantitatively relevant theory of multiple equilibria and nonfundamental fluctuations. In Benhabib and Farmer (1994), Farmer and Guo (1994), Christiano and Harrison (1999), and Mortensen (1999), multiplicity and nonfundamental shocks arise because of increasing returns to scale in production. Similarly, in Diamond (1982), Diamond and Fudenberg (1989), Howitt and McAfee (1992), and Boldrin, Kiyotaki, and Wright 
(1993), multiplicity is obtained because of increasing returns to scale in matching. In contrast to these papers, we assume constant returns to scale in both production and matching and obtain multiplicity from the differences in the shopping behavior of employed and unemployed buyers. Moreover, while there is no clear empirical evidence of increasing returns to scale in either production or matching, the differences in the shopping behavior of employed and unemployed buyers are well documented. In Heller (1986), Roberts (1987), and Cooper and John (1988), multiplicity is obtained because of demand externalities. The demand externality - which is due to the difference in the expenditures of employed and unemployed buyers - is an integral part of our theory as well. However, we find that the demand externality is quantitatively less important than the market power externality - which is due to the difference in the search intensity of employed and unemployed buyers - and, alone, it is not sufficient to generate multiplicity.

More recently, economists have advanced theories of nonfundamental fluctuations that do not stem from the existence of multiple perfect foresight equilibria. Benhabib, Wang, and Wen (2012) and Angeletos and La'O (2013) consider environments in which agents have heterogeneous beliefs about the gains from producing and trading. They show that nonfundamental fluctuations in economic activity can arise from correlated shocks to the agents' higher-order beliefs. In contrast to these papers, we assume that all agents have common knowledge. Farmer (2012a, 2012b) obtains nonfundamental fluctuations by letting wages be determined by sentiments rather than bargaining. As a result, in his models, nonfundamental shocks generate a positive correlation between wages of new hires and unemployment. In contrast, we assume that wages are uniquely pinned down by bargaining. Hence, in our model, nonfundamental shocks generate a negative correlation between wages of new hires and unemployment, the same correlation found in the data (see, e.g., Pissarides 2009).

\section{Environment and Equilibrium}

In this section, we describe our model economy and derive the conditions for equilibrium. In our model, workers and firms meet in a decentralized labor market with search frictions in the spirit of Mortensen and Pissarides (1994). Then, firm-worker pairs sell part of their output in a decentralized product market with search frictions in the spirit of Burdett and Judd (1983). The equilibrium conditions for our model economy are the same as in Mortensen and Pissarides's model except for one aspect. In their model, the revenues generated by a firm-worker pair are constant, as their output is sold in a perfectly competitive market where demand is infinitely elastic. In our model, the revenues generated 
by a firm-worker pair depend on the unemployment rate, as part of their output is sold in an imperfectly competitive market in which both the extent of competition and the level of demand depend on the unemployment rate. This small difference between our model and Mortensen and Pissarides's may be of great consequence. Indeed, as we shall see in Section III, if the revenues generated by a firm-worker pair negatively depend on unemployment, multiple equilibria may arise.

\section{A. Environment}

We consider a discrete-time, infinite-horizon economy populated by two types of agents - workers and firms - who exchange three goods-labor and two consumption goods. Labor is traded in a decentralized market with search frictions, modeled as in Mortensen and Pissarides (1994). The first consumption good is traded in a decentralized market with search frictions, modeled as in Burdett and Judd (1983). We shall refer to this good as the Burdett-Judd (BJ) good. The second consumption good is traded in a centralized and frictionless product market. We shall refer to this good as the Arrow-Debreu (AD) good.

The measure of workers in the economy is normalized to one. A worker has preferences described by the utility function $\sum_{t=0}^{\infty}(1+\rho)^{-t} u_{w}\left(x_{t}, y_{t}\right)$, where $1 /(1+\rho) \in(0,1)$ is the discount factor and $u_{w}(x, y)$ is a periodical utility function defined over consumption of the BJ good, $x$, and consumption of the $\mathrm{AD}$ good, $y$. We assume that $u_{w}(x, y)$ is of the CobbDouglas form $x^{\alpha} y^{1-\alpha}$, where $\alpha \in(0,1)$. A worker has access to a technology that allows him to transform the $\mathrm{AD}$ good into the $\mathrm{BJ}$ good at the rate of $r$ to 1, with $r>0$. This technology guarantees that a worker can consume some of the BJ good even when he fails to meet a seller in the $\mathrm{BJ}$ market. In every period, a worker is endowed with one indivisible unit of labor, which he may sell to a firm (if he has found an employer) or use for home production (if he is unemployed). When the worker is employed, his labor income is worth $w\left(u_{t}\right)$ units of the $\mathrm{AD}$ good, where $w\left(u_{t}\right)$ is a bargaining outcome that depends on the unemployment rate $u_{t}$. When the worker is unemployed, his labor income is worth $y_{u}$ units of the $\mathrm{AD}$ good, $y_{u} \geq 0$. This income can be interpreted as either the value of home production or the value of an unemployment benefit that is financed by lump-sum taxes levied on the firms. For the sake of simplicity, we assume that workers can neither borrow nor save income or goods across periods. ${ }^{1}$

\footnotetext{
${ }^{1}$ In the quantitative section of the paper, we will try to address this unrealistic feature of the model by making sure that the decline in expenditures experienced by a worker who becomes unemployed is in line with what we observe in the data.
} 
The measure of firms in the economy is also normalized to one. A firm has preferences described by the utility function $\sum_{t=0}^{\infty}(1+\rho)^{-t} u_{f}\left(x_{t}, y_{t}\right)-k v_{t}$, where $u_{f}\left(x_{t}, y_{t}\right)$ is a periodical utility function defined over consumption of the $\mathrm{BJ}$ and $\mathrm{AD}$ goods, $v_{t}$ is the number of vacancies created by the firm, and $k>0$ is the disutility cost of creating a vacancy. A firm creates vacancies in order to find employees. Every employee of the firm can produce any combination of $x$ units of the BJ good and $y$ units of the AD good such that $c x+y=y_{e}$, with $c \in(0, r)$ and $y_{e}>0$. The parameter $y_{e}$ describes the productivity of labor, measured in units of the $\mathrm{AD}$ good. The parameter $c$ describes the rate at which firm-worker matches can implicitly transform the $\mathrm{AD}$ good into the BJ good. As we shall see momentarily, the allocation of production between the $\mathrm{AD}$ and the $\mathrm{BJ}$ good depends on whether the firm-worker pair meets a buyer in the BJ market and, if so, on the quantity demanded by that buyer. For the sake of simplicity, we assume $u_{f}(x, y)=y$. That is, we assume that firms care only about consuming the $\mathrm{AD}$ good. ${ }^{2}$ Moreover, we assume that firms cannot store goods from one period to the next.

Markets open sequentially in every period $t$. The first market to open is the Mortensen-Pissarides (MP) labor market. In this market, firms create vacancies at the disutility cost $k$. Then unemployed workers, $u_{t-1}$, and vacant jobs, $v_{t}$, come together through a constant return to scale matching function $M\left(u_{t-1}, v_{t}\right)<\min \left\{u_{t-1}, v_{t}\right\}$. The probability that an unemployed worker matches with a vacancy is $\lambda\left(\theta_{t}\right) \equiv M\left(1, \theta_{t}\right)$, where $\theta_{t}$ denotes the tightness of the labor market, $v_{t} / u_{t-1}$, and $\lambda: \mathbb{R}_{+} \rightarrow[0,1]$ is a strictly increasing and concave function with boundary conditions $\lambda(0)=0$ and $\lambda(\infty)=1$. Similarly, the probability that a vacant job matches with an unemployed worker is $\eta\left(\theta_{t}\right) \equiv M\left(1 / \theta_{t}, 1\right)$, where $\eta: \mathbb{R}_{+} \rightarrow[0,1]$ is a strictly decreasing function with boundary conditions $\eta(0)=1$ and $\eta(\infty)=0$. When an unemployed worker and a vacant job match, they bargain over the current wage and enter the BJ and $\mathrm{AD}$ markets to produce and sell output. While vacant jobs and unemployed workers search for each other in the MP market, existing firmworker pairs are destroyed with probability $\delta \in(0,1)$.

The second market to open is the BJ product market. In this market, each firm-worker pair (henceforth, a seller) posts a price $p$, measured in units of the $\mathrm{AD}$ good, at which it is willing to sell the $\mathrm{BJ}$ good. Each worker (henceforth, a buyer) searches for sellers with an intensity that

\footnotetext{
${ }^{2}$ We assume that the owners of the firms are different agents than the workers. In particular, we assume that the owners of the firms have linear preferences over the AD good. The assumption implies that firms simply want to maximize the present value of profits measured in units of the AD good. If, in contrast, we were to assume that firms are owned by workers, firms would maximize the present value of profits with an endogenous discount factor that depends on the consumption path of workers. The model would be harder to solve, but we believe that the main results would still go through.
} 
depends on his employment status. In particular, if a buyer is unemployed, he makes one search with probability $1-\psi_{u}$ and two searches with probability $\psi_{u}$, where $\psi_{u} \in[0,1]$. If a buyer is employed, he makes one search with probability $1-\psi_{e}$ and two searches with probability $\psi_{e}$, where $\psi_{e} \in[0,1]$. We assume $\psi_{e} \leq \psi_{u}$ in order to capture the idea that a buyer has less time to search the product market when he is employed.

Sellers and buyers come together through a constant return to scale matching function $N\left(b\left(u_{t}\right), s\left(u_{t}\right)\right)$, where $b\left(u_{t}\right) \equiv 1+\psi_{e}+u\left(\psi_{u}-\psi_{e}\right)$ is the measure of buyers' searches, $s\left(u_{t}\right) \equiv 1-u_{t}$ is the measure of active sellers, and $u_{t}$ is the measure of unemployed workers at the opening of the BJ market. A seller meets a buyer with probability $\mu\left(\sigma\left(u_{t}\right)\right) \equiv$ $N\left(1 / \sigma\left(u_{t}\right), 1\right)$, where $\sigma\left(u_{t}\right)$ denotes the tightness of the product market, $s\left(u_{t}\right) / b\left(u_{t}\right)$. Similarly, a buyer who makes one search meets a seller with probability $\nu\left(\sigma\left(u_{t}\right)\right) \equiv N\left(1, \sigma\left(u_{t}\right)\right)$, while a buyer who makes two searches meets two sellers with probability $\nu\left(\sigma\left(u_{t}\right)\right)^{2}$ and one seller with probability $2 \nu\left(\sigma\left(u_{t}\right)\right)\left[1-\nu\left(\sigma\left(u_{t}\right)\right)\right]$. When a buyer meets a seller, it observes the price and decides whether and how much of the BJ good to purchase. We assume $N\left(b\left(u_{t}\right), s\left(u_{t}\right)\right)=\min \left\{b\left(u_{t}\right), s\left(u_{t}\right)\right\}$ in order to focus on search frictions (i.e., buyers meeting a random subset of sellers and sellers meeting random buyers) and abstract from matching frictions. ${ }^{3}$

The last market to open is the $\mathrm{AD}$ product market. In this market, each firm-worker pair produces and sells a quantity of $\mathrm{AD}$ goods that depends on the quantity of BJ goods it produced and sold in the BJ market. Each worker purchases and consumes an amount of AD goods that depends on the income that he spent in the $\mathrm{BJ}$ market. The $\mathrm{AD}$ market is frictionless and perfectly competitive. ${ }^{4}$

The medium of exchange in our economy is a perfectly divisible and transferable one-period IOU. In the MP market, firms pay wages to their workers by issuing IOUs promising a payment worth $w\left(u_{t}\right)$ units of $\mathrm{AD}$ goods in the current period. Firms also pay taxes to the government by issuing IOUs, which are then transferred by the government to unem-

\footnotetext{
${ }^{3}$ The theoretical results in Sec. III carry over to more general matching functions $N(b, s)$ with the property that the elasticity of $N$ with respect to $b$ is not too large.

${ }^{4}$ The AD goods and the $\mathrm{BJ}$ goods are two groups of consumer goods that differ with respect to the structure of the market where they are traded. The AD goods are traded in a perfectly competitive market, where the law of one price holds. The BJ goods are traded in an imperfectly competitive market where price dispersion obtains. We need both goods in our model. We need the BJ goods for substantive reasons. Indeed, our theory of multiplicity is based on the idea that the extent of competition in the product market is endogenous, and, hence, we need some goods to be traded in an imperfectly competitive market. We need the $\mathrm{AD}$ goods for technical reasons. In our model, the buyers of $\mathrm{BJ}$ goods compensate the sellers of $\mathrm{BJ}$ goods by giving them claims to contemporaneous $\mathrm{AD}$ goods. Hence, all trades are completed within each period. If the model did not have $\mathrm{AD}$ goods, buyers of BJ goods could pay only the sellers of BJ goods with claims to future BJ goods. Hence, trades would not be completed within each period and we would have to keep track of the credit/debit position of all the agents in the economy. The role of $\mathrm{AD}$ goods is to act as a medium of exchange, a sort of fiat money that is consumed and is perishable.
} 
ployed workers. In the BJ market, sellers exchange the BJ good for the IOUs carried by employed and unemployed buyers. In the $\mathrm{AD}$ market, firms use the IOUs that they have collected in the BJ market to purchase $\mathrm{AD}$ goods and they repay the IOUs that they have issued to their workers by selling $\mathrm{AD}$ goods.

It may be useful to point out the two features of the environment that are critical to our theory of self-fulfilling unemployment fluctuations. The first feature is that some of the output produced by a firm-worker pair is sold in an imperfectly competitive market (the BJ market), where the fraction of employed and unemployed buyers affects demand (because of differences in income) and the extent of competition (because of differences in search intensity). ${ }^{5}$ As we shall see, this feature implies that the revenues generated by a firm-worker output pair tend to decrease with unemployment. The second feature is that a firm needs to hire labor in order to enter or scale up its presence in the product market. ${ }^{6}$ As we shall see, this feature implies that when the product market features low demand and more competition, a firm demands less labor and creates fewer vacancies.

\section{B. Individual Problems and Terms of Trade}

Having described the environment, we now proceed to analyze the problem of individual agents and the determination of the terms of trade in the different markets.

\section{Individual Problems}

Problem of the buyer.-Consider an unemployed buyer who enters the BJ market with an income worth $y_{u}$ units of the AD good. With some probability, the buyer does not contact any seller in the BJ market. In this case, the buyer spends all of his income on the $\mathrm{AD}$ good and then transforms some of the $\mathrm{AD}$ goods into $\mathrm{BJ}$ goods at the rate of $r$ to 1 . With some probability, the buyer contacts one or two sellers. Let $p$ denote the lowest price of the BJ good among the sellers contacted by the buyer. If $p>r$, the buyer spends all of his income on the $\mathrm{AD}$ good and then transforms some of the $\mathrm{AD}$ good into the $\mathrm{BJ}$ good at the rate of $r$ to 1 . If $p \leq r$, the

\footnotetext{
${ }^{5}$ We refer the reader to Kaplan and Menzio (2013) for a discussion of alternative models of the product market that have the same feature.

${ }^{6}$ This feature follows from the assumption that each firm-worker pair represents a distinct seller in the product market. In the context of our search-theoretic model of imperfect competition, there is a natural interpretation for this assumption. New firms can enter the product market by opening a production-and-retail outlet and existing firms can expand their presence in the product market by opening additional outlets. Each outlet requires a fixed amount of labor for production and retail. Each outlet is a different seller because it is located in a different area and, hence, reaches a different set of buyers.
} 
buyer purchases both the $\mathrm{AD}$ good and the $\mathrm{BJ}$ good on the market. In particular, the buyer chooses how to allocate his income $y_{u}$ between consumption of the $\mathrm{BJ}$ good and consumption of the AD good so as to maximize its periodical utility function. Formally, the problem facing the buyer is

$$
\max _{x, y} x^{\alpha} y^{1-\alpha} \quad \text { subject to } p x+y=y_{u} .
$$

The solution to the problem of an unemployed buyer is

$$
p x=\alpha y_{u}, \quad y=(1-\alpha) y_{u} .
$$

That is, the buyer spends a fraction $\alpha$ of his income on the BJ good and a fraction $1-\alpha$ on the $\mathrm{AD}$ good. The solution to the problem of an employed buyer is the same as (2), except that the income is the wage $w\left(u_{t}\right)$ rather than the unemployment benefit $y_{u}$.

Problem of the seller.-Consider a seller entering the BJ market. The seller chooses the relative price of the BJ good so as to maximize its total revenues from sales in the $\mathrm{BJ}$ and $\mathrm{AD}$ markets. The seller takes as given the composition of buyers between employed and unemployed, the demand of each type of buyer, the total number of sellers, and the distribution of posted prices, an endogenous object that we shall denote as $F\left(p, u_{t}\right)$. Formally, the problem facing the seller is to maximize $S\left(p, u_{t}\right)+y_{e}$ with respect to $p$, where $S\left(p, u_{t}\right)$ denotes the seller's expected revenues in the $\mathrm{BJ}$ market net of the opportunity cost of producing the BJ good.

The net revenue function $S\left(p, u_{t}\right)$ is given by

$$
\begin{aligned}
S\left(p, u_{t}\right)= & \mu\left(\sigma\left(u_{t}\right)\right) \frac{u_{t}\left(1+\psi_{u}\right)}{b\left(u_{t}\right)}\left[1-\frac{2 \psi_{u} \nu\left(\sigma\left(u_{t}\right)\right) F\left(p, u_{t}\right)}{1+\psi_{u}}\right] \\
& \times \frac{\alpha y_{u}(p-c)}{p}+\mu\left(\sigma\left(u_{t}\right)\right) \frac{\left(1-u_{t}\right)\left(1+\psi_{e}\right)}{b\left(u_{t}\right)} \\
& \times\left[1-\frac{2 \psi_{e} \nu\left(\sigma\left(u_{t}\right)\right) F\left(p, u_{t}\right)}{1+\psi_{e}}\right] \frac{\alpha w\left(u_{t}\right)(p-c)}{p} .
\end{aligned}
$$

The net revenue function is given by the sum of two terms. Consider the first term. The probability that the seller meets a buyer is $\mu\left(\sigma\left(u_{t}\right)\right)$. The probability that the buyer is unemployed is $u_{t}\left(1+\psi_{u}\right) / b\left(u_{t}\right)$, the fraction of buyers' searches originating from unemployed workers divided by the total number of buyers' searches. Conditional on being unemployed, the probability that the buyer is not in contact with a seller charging a price less than $p$ is given by the term in brackets, which is equal to the complement to 1 of the product between the probability that the buyer is in contact with a second seller, $2 \psi_{u} \nu\left(\sigma\left(u_{t}\right)\right) /\left(1+\psi_{u}\right)$, and the probability that 
the second seller charges a price less than $p, F\left(p, u_{t}\right)$. Conditional on being unemployed and not being in contact with a seller charging less than $p$, the buyer purchases $\alpha y_{u} / p$ units of the BJ good. For every unit of the BJ good sold, the seller's revenue net of the opportunity cost of production is $p-c$. Summarizing, the first term in (3) represents the seller's expected net revenue from meetings with unemployed buyers. Similarly, the second term in (3) represents the seller's expected net revenue from meetings with employed buyers. The two terms differ because unemployed and employed buyers are willing to purchase at the price $p$ with different probabilities and because, when they do, they demand different quantities.

Problem of the firm. - Consider a firm entering the MP market. The firm decides how many vacancies to create by comparing the cost and the benefit of opening a vacancy. The cost of opening a vacancy is given by the disutility cost $k$. The benefit of opening a vacancy is given by the product of the probability of filling a vacancy, $\eta\left(\theta_{t}\right)$, and the present discounted value of the profits generated by an additional employee, $J_{t}$. Since the firm operates a constant return to scale technology, the value of an additional employee to the firm is independent of the number of workers employed by the firm, and hence, the firm's problem is linear. The solution of the problem is such that the firm does not open any vacancies if $k>J_{t}$, it opens infinitely many vacancies if $k<J_{t}$, and it is indifferent between opening any number of vacancies if $k=J_{t}$.

The value of an employee to the firm is such that

$$
J_{t}=\max _{p}\left[S\left(p, u_{t}\right)+y_{e}\right]-w\left(u_{t}\right)+\frac{1-\delta}{1+\rho} J_{t+1} .
$$

The above expression is easy to understand. In the current period, the firm collects $\max _{p}\left[S\left(p, u_{t}\right)+y_{e}\right]$ revenues in the $\mathrm{BJ}$ and $\mathrm{AD}$ markets and it pays the wage $w\left(u_{t}\right)$ to the worker. In the next period, the worker leaves the firm with probability $\delta$ and stays with the firm with probability $1-\delta$. In the first case, the continuation value of the employee is zero. In the second case, the continuation value of the employee is $J_{t+1}$.

\section{Terms of Trade and Market Tightness}

Terms of trade in the BJ market.- The distribution of posted prices in the BJ market, $F$, is consistent with the seller's optimal pricing strategy if and only if any price on the support of the distribution maximizes the seller's total revenues $S\left(p, u_{t}\right)+y_{e}$ or, equivalently, the seller's net revenues in the BJ market, $S\left(p, u_{t}\right)$. Lemma 1 states that there exists a unique price distribution that is consistent with the seller's optimal pricing strategy. The proof of the lemma is similar to the one in Burdett and Judd (1983) or in Head et al. (2012) and is presented in Appendix A. 
Lemma 1 (Equilibrium price distribution). The unique price distribution consistent with the seller's optimal pricing strategy is

$$
\begin{aligned}
F\left(p, u_{t}\right)= & \left(u_{t}\left(1+\psi_{u}\right)\left\{1-\left[1-\frac{2 \psi_{u} \nu\left(\sigma\left(u_{t}\right)\right)}{1+\psi_{u}}\right] \frac{(r-c) p}{(p-c) r}\right\} y_{u}\right. \\
& \left.+\left(1-u_{t}\right)\left(1+\psi_{e}\right)\left\{1-\left[1-\frac{2 \psi_{e} \nu\left(\sigma\left(u_{t}\right)\right)}{1+\psi_{e}}\right] \frac{(r-c) p}{(p-c) r}\right\} w\left(u_{t}\right)\right) \\
& \div 2 \nu\left(\sigma\left(u_{t}\right)\right)\left[u_{t} \psi_{u} y_{u}+\left(1-u_{t}\right) \psi_{e} w\left(u_{t}\right)\right]
\end{aligned}
$$

with support $\left[p_{t}, \bar{p}_{t}\right]$, where $c<\underline{p}_{t}<\bar{p}_{t}=r$.

The price distribution $F$ is continuous. In fact, if $F$ had a mass point at some $p_{0}>c$, a seller posting $p_{0}$ could increase its gains from trade by charging $p_{0}-\epsilon$. This deviation would increase the probability of making a sale by a discrete amount, but it would leave the net revenues on each unit sold approximately constant. ${ }^{7}$ The support of $F$ is connected. In fact, if the support of $F$ had a gap between $p_{0}$ and $p_{1}$, the seller's gains from trade would be strictly higher at $p_{1}$ than $p_{0}$, as the probability of making a sale is the same at $p_{0}$ and $p_{1}$ but the net revenues on each unit sold are strictly greater at $p_{1}$. For the same reason, the highest price on the support of $F$ is the buyer's reservation price $r$.

An implication of the previous lemma is that the maximized net revenues of the seller in the BJ market, $S^{*}\left(u_{t}\right)=\max _{p} S\left(p, u_{t}\right)$, are equal to the net revenues for a seller who charges the buyers' reservation price, that is, $r$, and sells only to captive buyers, that is, buyers that contact the seller and nobody else. That is, $S^{*}\left(u_{t}\right)$ is given by

$$
\begin{aligned}
S^{*}\left(u_{t}\right)= & \mu\left(\sigma\left(u_{t}\right)\right) \frac{u_{t}\left(1+\psi_{u}\right)}{b\left(u_{t}\right)}\left[1-\frac{2 \psi_{u} \nu\left(\sigma\left(u_{t}\right)\right)}{1+\psi_{u}}\right] \frac{\alpha y_{u}(r-c)}{r} \\
& +\mu\left(\sigma\left(u_{t}\right)\right) \frac{\left(1-u_{t}\right)\left(1+\psi_{e}\right)}{b\left(u_{t}\right)}\left[1-\frac{2 \psi_{e} \nu\left(\sigma\left(u_{t}\right)\right)}{1+\psi_{e}}\right] \\
& \times \frac{\alpha w\left(u_{t}\right)(r-c)}{r} .
\end{aligned}
$$

Terms of trade in the MP market.- The wage in the MP market is determined as the outcome of a bargaining process between the firm and the worker. We assume that the wage outcome is such that the additional income that the worker and the firm can generate together is divided between the worker and the firm according to the constant and exogenous

7 The price $p_{0}$ cannot be equal to $c$ because the seller's net revenues in the $\mathrm{BJ}$ market are always strictly positive. To see this, note that the seller's net revenues are bounded below by the (strictly positive) revenues associated with posting the reservation price $r$ and selling only to the buyers who are not in contact with any other seller. 
fractions $\gamma$ and $1-\gamma$, with $\gamma \in(0,1)$. Formally, we assume that the wage outcome is given by ${ }^{8}$

$$
w\left(u_{t}\right)=y_{u}+\gamma\left[S^{*}\left(u_{t}\right)+y_{e}-y_{u}\right] .
$$

The wage outcome in (7) coincides with the generalized Nash bargaining solution when the worker's and firm's outside options are as follows. The outside option of the worker is to enjoy an income worth $y_{u}$ units of the $\mathrm{AD}$ good, to make one search in the $\mathrm{BJ}$ market with probability $1-\psi_{e}$ and two searches with probability $\psi_{e}$, and to enter the next MP market still matched with the firm. The outside option of the firm is to generate no revenues from the worker in the $\mathrm{BJ}$ and $\mathrm{AD}$ markets and to enter the next MP market still matched with the worker. That is, a failure to agree on the terms of trade results in the firm and the worker not producing together in the current period and trying to agree on the terms of trade again in the next period. Moreover, a failure to agree on the terms of trade costs the worker some time and results in his searching the BJ market with the same intensity as an employed buyer. ${ }^{9}$

Tightness of the MP market.-The tightness of the MP market, $\theta_{t}$, is consistent with the firm's optimal vacancy creation strategy if and only if it is equal to

$$
\theta\left(J_{t}\right)= \begin{cases}0 & \text { if } k>J_{t} \\ \eta^{-1}\left(k / J_{t}\right) & \text { if } k \leq J_{t} .\end{cases}
$$

If the cost of creating a vacancy, $k$, is strictly greater than the value of an additional worker to the firm, $J_{t}$, the tightness of the MP market is zero. In fact, if $k>J_{t}$, the cost of creating a vacancy certainly exceeds the benefit of creating a vacancy, which is given by the probability of filling the vacancy times the value of a worker to the firm. If, on the other hand, $k$ is smaller than $J_{t}$, the tightness of the MP market is such that $\eta\left(\theta_{t}\right) J_{t}=k$. In fact, if $k \leq J_{t}$, firms continue to create new vacancies until the tightness of the MP market is high enough and, hence, the probability of filling a

\footnotetext{
${ }^{8}$ Since employed and unemployed workers pay different prices in the BJ market, the wage bargaining outcome (7) does not guarantee that a worker is better off employed than unemployed. In the theoretical part of the paper, we proceed under the assumption that employed workers are always better off. In the quantitative part of the paper, we verify that employed workers are better off than unemployed workers in all rational expectations equilibria.

9 The outside options here may be more or less realistic than the outside options in Pissarides (1985), Mortensen and Pissarides (1994), and many subsequent papers. They certainly simplify the analysis. The assumption that, in case of disagreement, the firm and the worker do not lose contact with each other simplifies the analysis by making the wage only a function of current variables. The assumption that, in case of disagreement, the worker searches with the same intensity as an employed buyer simplifies the analysis by making the wage independent of the price distribution $F$.
} 
vacancy is low enough to equalize the cost and the benefit of opening an additional vacancy.

\section{Unemployment Dynamics}

The law of motion for unemployment is

$$
u_{t}=u_{t-1}\left[1-\lambda\left(\theta_{t}\right)\right]+\left(1-u_{t-1}\right) \delta .
$$

The measure of unemployed workers at the opening of the MP market in period $t$ is $u_{t-1}$. During the MP market, an unemployed worker becomes employed with probability $\lambda\left(\theta_{t}\right)$ and an employed worker becomes unemployed with the exogenous probability $\delta$. Thus, the measure of unemployed workers at the opening of the BJ market in period $t$ is given by the right-hand side of (9). Clearly, this is also the measure of unemployed workers at the opening of the MP market in period $t+1$.

\section{Definition of Equilibrium}

We are now in the position to define an equilibrium for our model economy.

Definition 1. A discrete-time perfect foresight equilibrium is a sequence $\left\{J_{t}, u_{t}\right\}$ such that

i. for $t=0,1,2, \ldots, J_{t}$ satisfies the Bellman equation

$$
J_{t}=(1-\gamma)\left[S^{*}\left(u_{t}\right)+y_{e}-y_{u}\right]+\frac{1-\delta}{1+\rho} J_{t+1} ;
$$

ii. for $t=0,1,2, \ldots, u_{t}$ satisfies the law of motion

$$
u_{t}=u_{t-1}\left[1-\lambda\left(\theta\left(J_{t}\right)\right)\right]+\left(1-u_{t-1}\right) \delta
$$

iii. $\lim _{t \rightarrow \infty} J_{t}$ is finite and $u_{-1}$ is given.

Condition i is the Bellman equation (4) describing the value of an additional worker to a firm, where we have replaced the wage with its equilibrium value (7). Condition ii is equation (9) describing the law of motion for the unemployment rate. Finally, condition iii describes the boundary conditions for the system of differential equations defined by conditions $\mathrm{i}$ and ii. In particular, condition iii states that the initial value of unemployment is given and that the value of a worker to a firm satisfies a transversality condition. Given a sequence $\left\{J_{t}, u_{t}\right\}$ that satisfies the above equilibrium conditions, one can recover all the other equilibrium objects, such as the terms of trade in the MP and $\mathrm{BJ}$ markets (which are functions of the contemporaneous unemployment rate) and the 
tightness of the MP market (which is a function of the contemporaneous value of a worker).

In this section, which was mainly devoted to describing the environment and the equilibrium conditions, it was natural to make the assumption of discrete time. In the remainder of the paper, which is mainly devoted to characterizing the set of equilibria, it is more convenient to work in continuous time. We formally derive a continuous-time version of our discrete-time model in Appendix B. There, we assume that, over a period of length $\Delta$, the vacancy cost is $k \Delta$, the productivity of labor is $y_{e} \Delta$, the unemployment income is $y_{u} \Delta$, the job loss probability is $1-\exp (\delta \Delta)$, the MP matching function is $M(u, v) \Delta$, while the parameters $\psi_{e}, \psi_{u}, N, r$, and $c$ are independent of $\Delta$. We then take the limit as $\Delta$ goes to zero and obtain the continuous-time equivalent to the equilibrium conditions (10) and (11). This leads to the following definition of equilibrium for the continuous-time version of the model.

Definition 2. A continuous-time perfect foresight equilibrium is a path $\left\{u_{t}, J_{t}\right\}$ such that

i. for all $t \geq 0, J_{t}$ satisfies the Bellman equation

$$
(\rho+\delta) J_{t}=(1-\gamma)\left[S\left(u_{t}\right)+y_{e}-y_{u}\right]+\stackrel{\circ}{J}_{i}
$$

ii. for all $t \geq 0, u_{t}$ satisfies the law of motion

$$
\stackrel{\circ}{u}_{t}=-u_{t} \lambda\left(\theta\left(J_{t}\right)\right)+\left(1-u_{t}\right) \delta
$$

iii. $\lim _{t \rightarrow \infty} J_{t}$ is finite and $u_{0}$ is given.

\section{Equilibrium Characterization}

In this section, we characterize the equilibrium set for our model economy. In Section III.A, we analyze the set of steady states. We show that the revenues generated by a firm-worker pair are decreasing in unemployment if the income of employed buyers is sufficiently high relative to the income of unemployed buyers or if the search intensity of employed buyers in the $\mathrm{BJ}$ product market is sufficiently low relative to the search intensity of unemployed buyers. Moreover, we show that, if the revenues generated by a firm-worker pair are decreasing in unemployment, so are the firms' incentives to employ workers and, given an appropriate choice of the vacancy cost and the labor market matching function, the model admits multiple steady states. In Section III.B, we analyze the set of perfect foresight equilibria. If the model admits a unique steady state, we show that there is also a unique perfect foresight equilibrium for any initial condition of the economy. If the model admits multiple steady states, we show that there are always multiple perfect foresight equilibria for some initial conditions of the economy. These equilibria differ with re- 
spect to the agents' expectations about future unemployment. Hence, the behavior of our model economy is determined not only by fundamentals (i.e., technology and preferences) but also by expectations.

\section{A. Steady States}

A steady state is a point $(u, J)$ such that the unemployment rate and the value of a worker to a firm are stationary. In order to characterize the set of steady states, we use equation (13) to find the locus of points where the unemployment rate is stationary (henceforth, the $u$-nullcline) and equation (12) to find the locus of points where the value of a worker to a firm is stationary (henceforth, the J-nullcline). We then look for the set of intersections between the two loci.

The locus of points where unemployment is stationary is given by

$$
u=\frac{\delta}{\delta+\lambda(\theta(J))} .
$$

The stationary value of unemployment is given by the ratio of the worker's job loss rate, $\delta$, and the sum of the worker's job loss and the jobfinding rates, $\delta+\lambda(\theta(J))$. When the value to the firm from employing an additional worker, $J$, is smaller than the cost of creating a vacancy, $k$, the tightness of the MP market, $\theta(J)$, and the job-finding rate, $\lambda(\theta(J))$, are both equal to zero and, hence, the stationary value of unemployment is equal to $\bar{u} \equiv 1$. When $J$ is greater than $k, \theta(J)$ and $\lambda(\theta(J))$ are both strictly positive and strictly increasing in $J$. Hence, the stationary value of unemployment is strictly smaller than one and strictly decreasing in $J$. In the limit for $J \rightarrow \infty, \theta(J) \rightarrow \infty$ and $\lambda(\theta(J)) \rightarrow 1$. Hence, the stationary value of unemployment converges to $\underline{u} \equiv \delta /(1+\delta)$. Figure 1 plots the $u$-nullcline in the $(u, J)$-space.

The locus of points where the value of a worker to a firm is stationary is given by

$$
J=\frac{(1-\gamma)\left[S^{*}(u)+y_{e}-y_{u}\right]}{\rho+\delta}
$$

The stationary value of a worker is given by the flow of revenues generated by a firm-worker pair and accruing to the firm, $(1-\gamma)\left[S^{*}(u)+y_{e}-\right.$ $\left.y_{u}\right]$, capitalized by the factor $1 /(\rho+\delta)$. The stationary value of a worker is bounded because the flow revenues, $S^{*}(u)+y_{e}$, are bounded. Moreover, the stationary value of a worker is increasing, constant, or decreasing with respect to unemployment depending on whether the flow revenues are increasing, constant, or decreasing with respect to unemployment. Figure 1 illustrates several possible shapes for the $J$-nullcline in the $(u, J)$-space. 


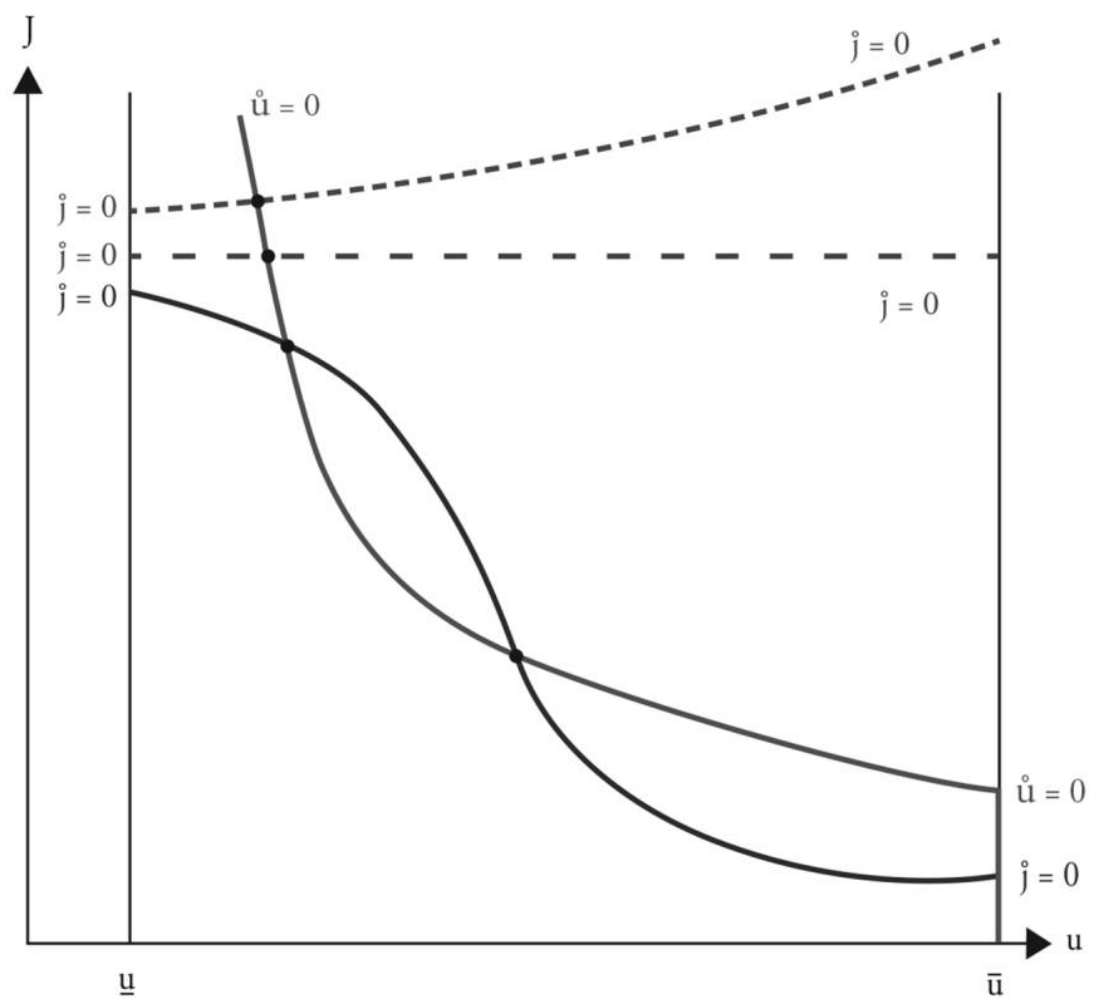

FIG. 1.-The $u$ - and $J$-nullclines. Color version available as an online enhancement.

From the properties of the $u$-nullcline and $J$-nullcline, we can already reach some general conclusions about the set of steady states. First, the model always admits one steady state, as the $u$-nullcline and the $J$ nullcline must cross at least once. Second, if the $J$-nullcline is constant or upward sloping, the model admits only one steady state. If, on the other hand, the $J$-nullcline is downward sloping, the model may admit multiple steady states. Whether this is the case depends on the exact shape of the $u$-nullcline, which depends on the vacancy cost, $k$, on the shape of the matching function in the MP market, $M$, and on the shape of the $J$-nullcline, which depends on the shape of the seller's revenue function $S^{*}(u)+y_{e}$.

In equilibrium, the seller's revenues are equal to the revenues for a seller that, in the BJ market, posts the reservation price $r$ and sells only to buyers who are not in contact with any other sellers (i.e., captive buyers). The derivative of the seller's revenues with respect to unemployment, $S^{* \prime}(u)$, is a complicated expression that can be written as the 
sum of three terms - the market power effect $M E(u)$, the demand effect DE $(u)$, and the tightness effect TE $(u)$ — scaled up by a multiplier $1 /[1-M L T(u)]$. That is, the derivative of the seller's revenues can be written as

$$
S^{* \prime}(u)=\frac{M E(u)+D E(u)+T E(u)}{1-M L T(u)} .
$$

The market power effect of unemployment is given by

$$
\begin{aligned}
M E(u)= & -\frac{\left(1+\psi_{u}\right)\left(1+\psi_{e}\right)}{b(u)^{2}} \cdot\left[\frac{2 \psi_{u}}{1+\psi_{u}} \frac{1-u}{b(u)}-\frac{2 \psi_{e}}{1+\psi_{e}} \frac{1-u}{b(u)}\right] \\
& \cdot \frac{\alpha y_{u}(r-c)}{r} .
\end{aligned}
$$

The first term in the expression above is the derivative with respect to unemployment of the probability that, in the BJ market, the seller meets a buyer who is employed rather than unemployed. The second term is the difference between the probability that a buyer is captive conditional on being employed rather than unemployed. The last term is the seller's revenue (net of the opportunity cost of production) from making a sale to an unemployed buyer. Thus, the market power effect measures the decline in the seller's revenues caused by the fact that an increase in unemployment raises the seller's probability of meeting an unemployed buyer and, since unemployed buyers search more, lowers the probability that the buyer is captive.

The demand effect of unemployment is given by

$$
\begin{aligned}
D E(u)=- & \frac{\left(1+\psi_{u}\right)\left(1+\psi_{e}\right)}{b(u)^{2}} \cdot\left[1-\frac{2 \psi_{e}}{1+\psi_{e}} \frac{1-u}{b(u)}\right] \\
& \cdot \frac{\alpha\left(w(u)-y_{u}\right)(r-c)}{r} .
\end{aligned}
$$

The first term in the expression above is derivative with respect to unemployment of the probability that, in the BJ market, the seller meets a buyer who is employed rather than unemployed. The second term is the probability that an employed buyer is captive. The last term is the difference between the net revenues that the seller makes if it sells to a buyer who is employed rather than unemployed. Thus, the demand effect measures the decline in the seller's revenues caused by the fact that an increase in unemployment raises the seller's probability of meeting an unemployed buyer, and since unemployed buyers have lower income, it lowers the quantity demanded by a captive buyer. 
The tightness effect of unemployment is given by

$$
\begin{aligned}
T E(u)= & \frac{u\left(1+\psi_{u}\right)}{b(u)} \cdot \frac{2 \psi_{u}}{b(u)^{2}} \cdot \frac{\alpha y_{u}(r-c)}{r} \\
& +\frac{1+\psi_{e}(1-u)}{b(u)} \cdot \frac{2 \psi_{e}\left(1+\psi_{u}\right)}{b(u)^{2}\left(1+\psi_{e}\right)} \cdot \frac{\alpha w(u)(r-c)}{r} .
\end{aligned}
$$

The tightness effect measures the increase in the seller's net revenues due to the fact that an increase in unemployment lowers the seller-tobuyer ratio in the $\mathrm{BJ}$ market and, hence, increases the probability that a buyer in a particular employment state is captive. Formally, the first line is the product of the seller's probability of meeting a buyer who is unemployed, the derivative with respect to unemployment of the probability that the buyer is captive, and the seller's net revenues from trading with the buyer. Similarly, the second line is the product of the seller's probability of meeting a buyer who is employed, the derivative with respect to unemployment of the probability that the buyer is captive, and the seller's revenues from trading with the buyer.

An increase in unemployment affects the sellers' revenues through the market power, demand, and tightness effects. But by affecting the sellers' revenues, an increase in unemployment also affects the wage of employed workers, the quantity sold by sellers upon meeting a captive employed buyer, and, in the end, the sellers' revenues. This feedback effect between revenues and wages multiplies the market power, the demand, and the tightness effects by the factor $1 /[1-M L T(u)]$, where $\operatorname{MLT}(u)$ is given by

$$
\operatorname{MLT}(u)=\frac{\left(1+\psi_{e}\right)(1-u)}{b(u)}\left[1-\frac{2 \psi_{e}}{1+\psi_{e}} \frac{1-u}{b(u)}\right] \frac{\gamma \alpha(r-c)}{r},
$$

which is the derivative of the seller's revenues with respect to the wage of employed workers times the derivative of the wage of an employed worker with respect to the revenues he and his employer generate.

Overall, the sign of the derivative of the seller's revenues with respect to unemployment - and, hence, the slope of the $J$-nullcline-is negative if the demand and the market power effects dominate and positive if the tightness effect dominates. The following theorem provides two necessary and sufficient conditions under which the derivative of the seller's revenues is negative and, hence, the $J$-nullcline downward sloping. Further, the theorem proves that, when $S^{* \prime}(u)$ is negative, one can find parameter values such that the $u$-nullcline crosses the $J$-nullcline multiple times.

Theorem 1 (Multiplicity of steady states). (i) For any $u \in[\underline{u}, \bar{u}]$ there is a $\bar{y}_{e}(u) \geq y_{u}$ such that $S^{* \prime}(u)<0$ iff $y_{e}>\bar{y}_{e}(u)$. (ii) There exists a $\tilde{u}>0$ 
such that, for any $u \in[\underline{u}, \tilde{u}]$, there is a $\bar{\psi}_{e}(u) \leq \psi_{u}$ such that $S^{* \prime}(u)<0$ iff $0 \leq \psi_{e}<\bar{\psi}_{e}(u)$. (iii) Iff $S^{* \prime}(u)<0$ for some $u \in[\underline{u}, \bar{u}]$, there is a vacancy cost $k$ and a labor market matching function $M$ such that the model admits multiple steady states.

Proof. See Appendix C.

The first part of theorem 1 states that the seller's revenues are decreasing in unemployment if and only if the productivity of labor, $y_{e}$, is sufficiently high relative to the income of the unemployed, $y_{u}$. This result is intuitive. The higher $y_{e}$ is relative to $y_{u}$, the larger the difference in income between employed and unemployed workers and, hence, the larger the demand effect of unemployment. The second part of theorem 1 states that the seller's revenues are decreasing in unemployment if and only if the search intensity of employed buyers, $\psi_{e}$, is sufficiently small relative to the search intensity of employed buyers, $\psi_{u}$. This result is also intuitive. The lower $\psi_{e}$ is relative to $\psi_{u}$, the larger the difference between the probabilities than an employed buyer and an unemployed buyer are captive and, hence, the larger the market power effect of unemployment. The last part of theorem 1 states that, if and only if the seller's revenues are decreasing in unemployment, one can find a value for the vacancy cost, $k$, and a legitimate matching function, $M$, such that the $u$-nullcline crosses the $J$-nullcline multiple times and, hence, the model admits multiple steady states. Intuitively, if $S^{* \prime}(u)<0$, a higher unemployment rate lowers the firm's value of hiring a worker, it lowers the firm's incentive to create vacancies, and if the matching function $M$ is chosen appropriately, the decline in vacancy creation sustains the higher unemployment rate.

It is useful to interpret the existence of multiple steady states as the outcome of the externalities that a firm imposes on other firms if it permanently increases its workforce. If a firm increases its workforce, it increases the other firms' cost of hiring an additional worker by increasing the tightness of the labor market. We refer to this external effect as the congestion externality. The congestion externality is negative, and its strength is measured by the slope of the $u$-nullcline. Moreover, if a firm decides to increase its workforce, it affects the other firms' benefit from hiring an additional worker by lowering the unemployment rate and, thus, increasing the tightness of the product market and changing the composition of the buyers populating it. The increase in the tightness of the product market lowers the other firms' benefit from hiring an additional worker as it lowers the probability that a firm-worker pair meets an employed or unemployed buyer who is captive. This external effect is captured by the TE term in (19). The change in the composition of buyers increases the other firms' benefit from hiring an additional worker as it increases the probability that a firm-worker pair meets an employed 
buyer, which is the type that demands more and is more likely to be captive. This external effect is captured by the $M E$ and $D E$ terms in (17) and (18). We refer to the sum of $T E, M E$, and $D E$ as the shopping externalities of employment. The shopping externalities may be positive or negative, and their strength is measured by the slope of the $J$-nullcline.

If, at some steady state, the shopping externalities are positive and dominate the congestion externality, the employment decisions of different firms are strategic complements, in the sense that if a firm increases its workforce, other firms want to increase their workforce as well. This strategic complementarity in employment leads to multiple steady states. Graphically, if, at some steady state, the shopping externalities are positive and dominate the congestion externality, the $J$-nullcline is downward sloping and crosses the $u$-nullcline from above, which, as one can see from figure 1, guarantees the existence of multiple intersections between the two curves.

The existence of multiple steady states rests on the demand and the market power externalities, which, in turn, originate from the fact that employed buyers demand more and search less than unemployed ones. Theoretically, either one of these externalities in isolation is sufficient to obtain multiplicity. Indeed, one can easily verify that the seller's revenues can be decreasing in unemployment (and, by virtue of theorem 1 , multiplicity may emerge) even when the search intensity of employed and unemployed buyers is the same and, hence, the market power externality is shut off. Similarly, one can easily verify that the seller's revenues can be decreasing in unemployment even when the income of employed and unemployed workers is the same and, hence, the demand externality is shut off. Empirically, though, we shall see that the market power externality - which is the genuinely novel feature of our theory-is more important than the demand externality.

\section{B. Perfect Foresight Equilibria}

When the model admits only one steady state, it is easy to prove that there exists a unique perfect foresight equilibrium for any initial unemployment rate. When the model admits multiple steady states, the characterization of the set of perfect foresight equilibria is more complicated. First, we need to characterize the solutions of the dynamical system given by the differential equations (12) and (13) around each steady state. Second, we need to characterize the solutions of the dynamical system (12)(13) away from the steady states. Finally, we need to check the transversality condition in order to understand which solutions are indeed perfect foresight equilibria. For the sake of concreteness, we will carry out the analysis for the case in which there are three steady states. 
Let $E_{i}=\left(u_{i}^{*}, J_{i}^{*}\right)$ denote the steady state with the $i$ th-lowest unemployment rate. The linear approximation of the dynamical system (12)-(13) around $E_{i}$ is

$$
\left(\begin{array}{c}
\stackrel{\circ}{t}_{t} \\
\stackrel{\circ}{J_{t}}
\end{array}\right)=\left(\begin{array}{cc}
-\delta-\lambda\left(\theta\left(J_{i}^{*}\right)\right) & -\lambda^{\prime}\left(\theta\left(J_{i}^{*}\right)\right) \theta^{\prime}\left(J_{i}^{*}\right) \\
-(1-\gamma) S^{* \prime}\left(u_{i}^{*}\right) & \rho+\delta
\end{array}\right)\left(\begin{array}{c}
u_{t}-u_{i}^{*} \\
J_{t}-J_{i}^{*}
\end{array}\right) .
$$

The behavior of the dynamical system (12)-(13) in a neighborhood of the steady state $E_{i}$ depends on the sign of the two eigenvalues of the $2 \times 2$ matrix in (21). At the steady state with the lowest unemployment rate, $E_{1}$, the two eigenvalues are real and have opposite signs. This means that the steady state is a saddle and, hence, there exists one and only one trajectory - the stable manifold - that converges toward $E_{1}$. We find it useful to denote as $J_{1}^{S}(u)$ the set of $J$ 's such that the point $(u, J)$ belongs to the stable manifold converging to $E_{1}$. At the steady state with the intermediate unemployment rate, $E_{2}$, the two eigenvalues are complex conjugates. The sign of the real part of these eigenvalues is negative if $u_{i}^{*}<\delta /(\rho+\delta)$ and positive if $u_{i}^{*}>\delta /(\rho+\delta)$. This means that, if $u_{i}^{*}<$ $\delta /(\rho+\delta)$, the steady state is a sink and, hence, any trajectory starting in a neighborhood of $E_{2}$ converges toward $E_{2}$. If $u_{i}^{*}>\delta /(\rho+\delta)$, the steady state is a source and, hence, any trajectory starting in a neighborhood of $E_{2}$ diverges from $E_{2}$. Finally, at the steady state with the highest unemployment rate, $E_{3}$, the two eigenvalues are real and have opposite signs. Hence, the steady state $E_{3}$ is also a saddle. We denote as $J_{3}^{S}(u)$ the set of $J$ 's such that the point $(u, J)$ belongs to the stable manifold converging to $E_{3}$.

The global behavior of the dynamical system (12)-(13) depends on the shape of the stable manifolds associated with the steady states $E_{1}$ and $E_{3}$ and on whether the steady state $E_{2}$ is a source or a sink. Figure 2 illustrates the solutions of the dynamical system (12)-(13) when (i) the backward extension of $J_{1}^{S}$ to the left of $E_{1}$ exits from $\underline{u}$ and the backward extension of $J_{1}^{S}$ to the right of $E_{1}$ exits from $\bar{u}$; (ii) the backward extension of $J_{3}^{S}$ to the left of $E_{3}$ exits from $\underline{u}$ and the backward extension of $J_{3}^{S}$ to the right of $E_{3}$ exits from $\bar{u}$; (iii) $E_{2}$ is a sink. Fix any initial unemployment $u_{0} \in[\underline{u}, \bar{u}]$. First, consider the point $\left(u_{0}, J_{0}\right)$, where $J_{0}=J_{1}^{S}\left(u_{0}\right)$. The solution to the dynamical system starting from $\left(u_{0}, J_{0}\right)$ is the stable manifold that converges to $E_{1}$. This trajectory is an equilibrium because it satisfies the differential equations (12) and (13) in definition 2 as well as the transversality condition. Second, consider the point $\left(u_{0}, J_{0}\right)$, where $J_{0}=J_{3}^{S}\left(u_{0}\right)$. The solution to the dynamical system starting from $\left(u_{0}, J_{0}\right)$ is the stable manifold that converges to $E_{3}$. Clearly, this trajectory is also an equilibrium. Third, consider any point $\left(u_{0}, J_{0}\right)$, where $J_{0} \in\left(J_{3}^{S}\left(u_{0}\right), J_{1}^{S}\left(u_{0}\right)\right)$. Given the initial condition $\left(u_{0}, J_{0}\right)$, the solution 


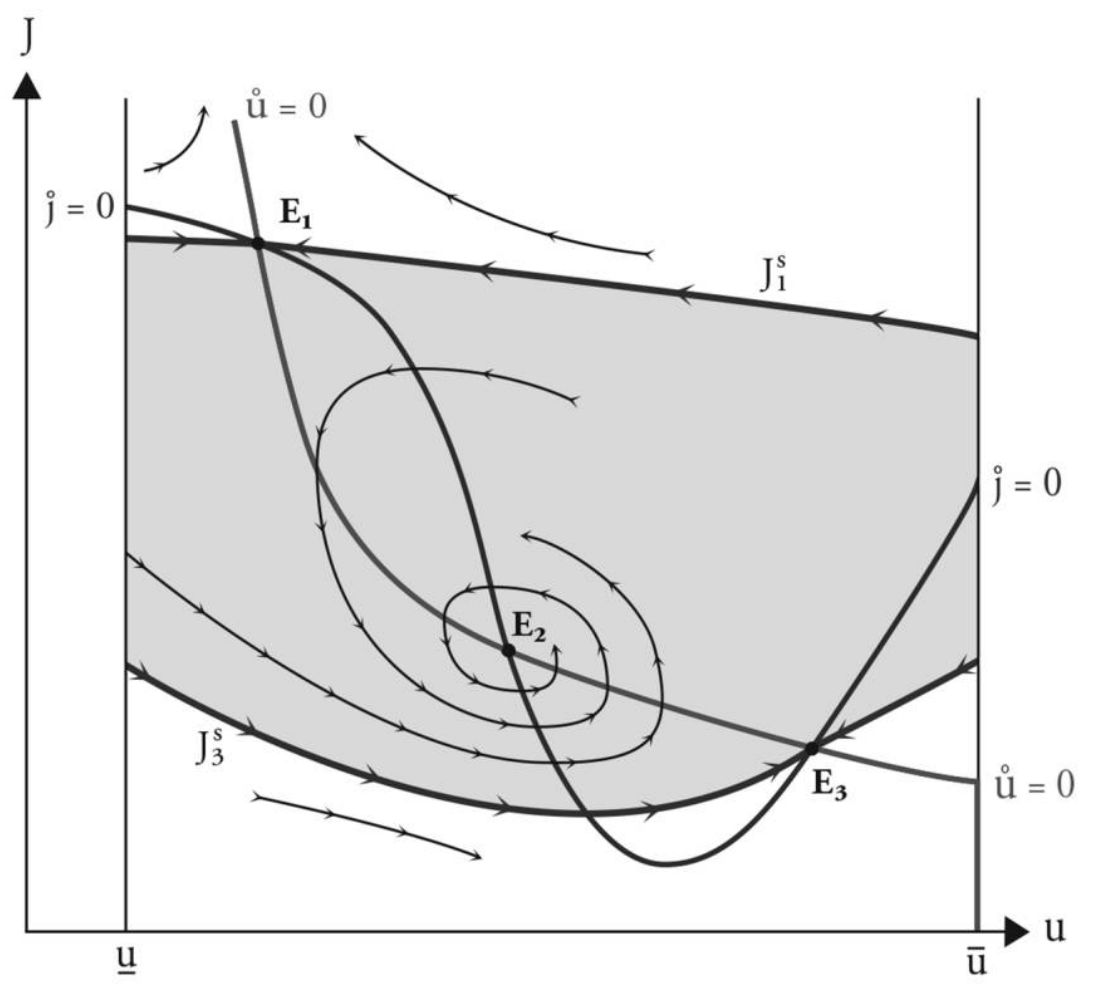

FIG. 2.-Perfect foresight equilibria. Color version available as an online enhancement.

to the dynamical system is a trajectory that remains in the shaded area in figure 2 and converges to either $E_{2}$ or a limit cycle surrounding $E_{2}$. Clearly, the trajectory constitutes an equilibrium in either case. Finally, consider any point $\left(u_{0}, J_{0}\right)$, where $J_{0} \notin\left[J_{3}^{S}\left(u_{0}\right), J_{1}^{S}\left(u_{0}\right)\right]$. Given the initial condition $\left(u_{0}, J_{0}\right)$, the solution to the dynamical system is a trajectory such that the value of the worker to a firm, $J_{t}$, diverges to plus or minus infinity. Hence, the trajectory does not constitute an equilibrium because it violates the transversality condition. Overall, for any initial unemployment $u_{0}$, there are three types of equilibria: the stable manifold converging to $E_{1}$, the stable manifold converging to $E_{3}$, and a continuum of equilibria starting between the two stable manifolds and converging to either $E_{2}$ or a limit cycle around $E_{2}$.

In Appendix D, we characterize the solutions to the dynamical system (12)-(13) and the set of equilibria when $E_{2}$ is a sink-which is the relevant case for most reasonable parameterizations of the modeland the stable manifolds associated with $E_{1}$ and $E_{3}$ take on shapes differ- 
ent from those in figure 2. All of these cases share two key features with the one illustrated in figure 2. First, there are initial unemployment rates for which the model admits multiple equilibria. These equilibria differ with respect to the agents' expectations about future unemployment. However, in each one of these equilibria, the agents' expectations are correct in the sense that the realized path of unemployment coincides with the one expected by the agents. The existence of multiple equilibria occurs because the expectation of higher unemployment in the future lowers the firm's value of a worker, it lowers the firm's incentives to create vacancies now, and, in turn, fewer vacancies fulfill the expectation of higher future unemployment. The existence of multiple equilibria implies that the behavior of our model economy is determined not only by fundamentals (e.g., preferences and technology) but also by the agents' expectations about future unemployment.

Second, there are initial unemployment rates for which the model admits equilibria that converge to different steady states. The coexistence of equilibria converging to different steady states means that the agents' expectations can be so important as to determine the long-run outcomes of the economy, and not simply the path that the economy follows in the short run. This is a key feature of our model. In our model - as in any textbook search models of the labor market - the transition of the economy toward the steady state is rapid because, empirically, workers move rather quickly in and out of unemployment. Therefore, changes in the agents' expectations could not possibly have a significant impact on labor market outcomes if these expectations affected the transition path of the economy only toward the steady state, and not the steady state toward which the economy is headed.

\section{Calibration and Validation}

In this section, we quantify our theory of multiplicity. In Sections IV.A and IV.B, we calibrate the parameters of the model so as to match US data on the difference in shopping behavior between employed and unemployed workers, on the rate at which workers transit between employment and unemployment, and on the distribution of prices at which identical goods trade in the same market and in the same period of time. In Section IV.C, we show that the calibrated model admits multiple steady states. Moreover, for any initial condition, we show that the calibrated model admits multiple perfect foresight equilibria and that some of these equilibria converge to different steady states. Multiplicity is obtained because unemployment has a strong negative effect on the revenues generated by a firm-worker pair and, hence, on the firms' incentives to hire. In turn, unemployment has a strong negative effect on the revenues generated by a firm-worker pair not so much because un- 
employed buyers spend less than employed buyers, but because unemployed buyers spend more time searching for low prices and, in doing so, they increase the competitiveness of the product market. In Section IV.D, we provide some empirical evidence to validate the key mechanisms of our model.

\section{A. Calibration Strategy}

Preferences are described by the discount factor, $\rho$, and by the periodical utility function of workers, $u_{w}(x, y)=x^{\alpha} y^{1-\alpha}$, and firms, $u_{f}(x, y)=y$. The technology operated by firm-worker pairs is described by the productivity of labor measured in units of the AD good, $y_{e}$, and by the implicit rate of transformation of the $\mathrm{AD}$ good in the $\mathrm{BJ}$ good, $c$. The technology operated by workers is described by the value of home production/unemployment benefits measured in units of the $\mathrm{AD}$ good, $y_{u}$, and by the rate of transformation of the $\mathrm{AD}$ good in the $\mathrm{BJ}$ good, $r$. Search and bargaining in the MP market are described by the vacancy cost, $k$; by the matching function $M$, which we assume to be of the constant elasticity of substitution form $M(u, v)=u v\left(u^{\phi}+v^{\phi}\right)^{-1 / \phi}$; by the worker's bargaining power, $\gamma$; and by the job loss rate, $\delta$. The search frictions in the BJ market are described by the probability that an unemployed worker searches twice, $\psi_{u}$, by the probability that an employed worker searches twice, $\psi_{e}$, and by the matching function $N$, which we assume to be of the form $N(b, s)=\min \{b, s\}$.

The model is described by a total of 12 parameters. The value of these parameters is chosen so that the model, evaluated at the steady state with the lowest unemployment, matches features of the US economy over the period 1987-2007. We choose the vacancy cost, $k$, and the job loss rate, $\delta$, so that the model matches the average of the worker's monthly transition rates between unemployment and employment (the UE rate) and between employment and unemployment (the EU rate). We choose the parameter $\phi$ in the MP matching function so that the model matches the elasticity of the UE rate with respect to the vacancy to unemployment ratio. This part of our calibration strategy is standard (see, e.g., Shimer 2005).

The calibration strategy for the remaining nine parameters is novel and we shall describe it in greater detail. We normalize labor productivity, $y_{e}$, to one and we choose $y_{u}$ so that the model matches the ratio of expenditures of unemployed workers to the expenditures of employed workers. This is an appropriate calibration target because, in the model, the unemployed/employed expenditure ratio, $y_{u} / w$, is increasing in $y_{u}$. We assume that the market rate of transformation of the AD good into the $\mathrm{BJ}$ good, $c$, equals one, and we choose the home rate of transformation, $r$, so that the model matches the average ratio of the highest price 
to the lowest price at which an identical good is traded in the same market and during the same period of time. This is an appropriate target because, in the model, the highest-to-lowest price ratio is increasing in $r$. The profit margin enjoyed by a firm, $(1-\gamma)\left[S^{*}(u)+y_{e}-y_{u}\right] /\left[S^{*}(u)+\right.$ $\left.y_{e}\right]$, is decreasing in the worker's bargaining power $\gamma$. Thus, we choose $\gamma$ so as to match a measure of profit rates.

We choose the search intensities $\psi_{u}$ and $\psi_{e}$ so that the model matches the ratio of the time spent shopping by unemployed workers to the time spent shopping by employed workers, as well as the ratio of the prices paid by unemployed workers to the prices paid by employed workers. These are natural targets. Under the assumption that the average number of searches is proportional to the time spent shopping, one can recover $\left(1+\psi_{u}\right) /\left(1+\psi_{e}\right)$ from the difference in the amount of time spent shopping by unemployed and employed workers. Then, one can recover $\psi_{e}$ from the difference in prices paid by unemployed and employed workers because the return of $\psi_{u}-\psi_{e}$ additional searches (measured by the decline in the prices paid) is decreasing in $\psi_{e}$. Finally, we choose $\alpha$ so that the model matches the average standard deviation of prices for identical goods. Intuitively, $\alpha$ determines the size of the BJ market (where there is price dispersion) and the size of the AD market (where there is no price dispersion) and, hence, it determines the average dispersion of prices.

\section{B. Data Sources and Target Values}

Table 1 summarizes the values of the empirical moments used to calibrate the parameters of the model. We measure the workers' transition rates between employment and unemployment following the methodology developed by Shimer (2005). Over the period 1987-2007, we find that the average monthly UE rate was 43 percent per month and the average monthly EU rate was 2.4 percent. Over the same period, we find that the elasticity of the UE rate with respect to the vacancy-tounemployment rate was approximately 25 percent. However, as discussed in Petrongolo and Pissarides (2001) and Menzio and Shi (2011), this is a biased estimate of the elasticity of the UE rate with respect to labor market tightness because, in reality, both employed and unemployed workers search for jobs. Hence, we choose to target an elasticity of the UE rate with respect to $\theta$ of 65 percent, which is the value estimated by Menzio and Shi after accounting for search on the job. In Appendix E, we consider alternative calibrations in which the targeted elasticity varies between 45 and 70 percent.

We measure the difference in expenditures between employed and unemployed workers using several existing estimates for the decline in expenditures experienced by households that transit from employment 
TABLE 1

Calibration Targets

\begin{tabular}{lr}
\hline \hline & Value \\
\hline Product market targets: & \\
Expenditures of U relative to E & .85 \\
Shopping time of U relative to E & 1.25 \\
Standard deviation log prices & .15 \\
Max-min ratio & 1.70 \\
Price paid by U relative to E & .98 \\
Labor market targets: & .433 \\
Monthly transition rate, UE & .024 \\
Monthly transition rate, EU & .650 \\
Elasticity UE with respect to tightness & .05 \\
Other targets: & .035 \\
Profit margin & \\
Real annual interest rate &
\end{tabular}

to unemployment. Using the Panel Study of Income Dynamics (PSID), Bentolila and Ichino (2008) find that a year of unemployment leads a 19 percent decline in food expenditures. Restricting attention to households that move into unemployment because of either business closures or mass layoffs, Stephens (2001) finds that a year of unemployment leads to a 14 percent decline in food expenditures. Stephens (2004) obtains similar findings using data from the Health and Retirement Survey in addition to the PSID. On the basis of these estimates, we choose to target a 15 percent difference in expenditures between employed and unemployed workers. ${ }^{10}$ In Appendix E, we vary this target between 10 and 40 percent.

We measure the difference in shopping time between employed and unemployed workers using cross-sectional data from the American Time Use Survey. Restricting attention to individuals aged 22-55, we find that employed people spend between 24 and 33 percent less time shopping than nonemployed people and between 13 and 20 percent less than unemployed people. ${ }^{11}$ Using similar data, Krueger and Mueller (2010) find a difference in shopping time between employed and unemployed indi-

${ }^{10}$ The difference between employed and unemployed workers with respect to food expenditures is presumably a lower bound on the difference with respect to total expenditures. As the reader can see in App. E, targeting a larger expenditure difference would strengthen the case for multiplicity.

11 The estimation results vary depending on the definition of shopping time. We consider a broad definition of shopping time that includes time spent purchasing all goods and services plus related travel time and a narrow definition of shopping time that includes time spent purchasing consumer goods and groceries plus related travel time. All details are available on request. 
viduals of 29 percent in the United States, 67 percent in Canada and western Europe, and 56 percent in eastern Europe. On the basis of these findings, we choose to target a 25 percent difference in shopping time between employed and unemployed workers. In Appendix E, we let this target vary between 10 and 50 percent.

We measure price dispersion using the Kielts-Nielsen Consumer Panel Data (KNCPD). ${ }^{12}$ We consider different definitions of a good. For the narrowest definition of a good, we group together all products that have different bar codes but are identical along all other dimensions (i.e., brand, size, color, shape, packaging, etc.). For the broadest definition of a good, we group together all products that are identical except for their bar code, brand, and size. We define a market as a Scantrack Market Area, which is the notion of market used by Nielsen. We define a time period as a quarter. For each good, market, and quarter, we compute the standard deviation of prices and various percentile ranges. We find that the average standard deviation of prices ranges between 19 and 36 percent and that the average 90-to-10 percentile ratio ranges between 1.7 and 2.6, depending on the definition of a good. Considering that some price dispersion is probably caused by factors that are not in our model (e.g., sellers' heterogeneity), we choose to target a standard deviation of prices of 15 percent and a max-to-min price ratio of 1.7. In Appendix E, we consider alternative values for these targets.

We measure the difference in prices paid by employed and nonemployed households following the methodology developed by Aguiar and Hurst (2007). For each household aged 25-55 in the KNCPD, we compute a price index defined as the ratio of the household's actual expenditures to the counterfactual expenditures that the household would have incurred if it had purchased goods at their average market price. We then regress the household's price index on the household's employment status and on a number of other household characteristics. We find that the presence of an additional nonemployed head in the household leads to a decline in the household's price index ranging between 1 and 3.5 percent. Moreover, we find that at most one-third of the decline in the household's price index can be accounted for by the expensiveness of the stores at which the household shops. On the basis of these findings, we choose to target a difference in prices paid by employed and unemployed workers of 2 percent.

\footnotetext{
${ }^{12}$ The KNCPD is a panel data set covering approximately 50,000 households over the period 2004-9. Respondents use in-home Universal Product Code scanning devices to record information (price, quantity, outlet, etc.) about their purchases of grocery and nongrocery household items, which account for roughly 30 percent of total expenditures. The reader can find all the details about the data and the measurement of price dispersion and price indexes in Kaplan and Menzio (2015).
} 


\section{Properties of the Calibrated Model}

Table 2 reports the calibrated parameter values. Given these values, we find that the model admits three steady states. At the first steady state, the unemployment rate is 5.3 percent and the value of a worker to a firm is 11.3 units of the $\mathrm{AD}$ good. At the intermediate steady state, the unemployment rate is 8.1 percent and the value of a worker to a firm is 9.5 units of the $\mathrm{AD}$ good. At the last steady state, there is no economic activity as the unemployment rate is 100 percent. Moreover, we find that the set of perfect foresight equilibria is as in figure 2: For any initial unemployment rate, there is an equilibrium converging to the low unemployment steady state, one equilibrium converging to the high unemployment steady state, and a continuum of equilibria converging to the intermediate steady state.

The existence of multiple steady states and, hence, multiple equilibria is easy to understand. The model is calibrated to have a crossing between the $u$-nullcline and the $J$-nullcline at an unemployment rate of 5.3 percent. The $u$-nullcline-whose shape is determined exclusively by standard labor market calibration targets - implies that there will be a second steady state with an unemployment rate below 10 percent if the $J$-nullcline falls by at least 20 percent as unemployment increases from 5.3 percent to 10 percent. The semielasticity of the $J$-nullcline with respect to unemployment - which depends on the product market calibration targets - is given by

$$
E_{J, u}=\frac{y_{e}+S^{*}(u)}{y_{e}-y_{u}+S^{*}(u)} E_{R, u},
$$

TABLE 2

Calibrated Parameters

\begin{tabular}{lc}
\hline \hline Parameter & Value \\
\hline Preference parameters: & .003 \\
$\quad \rho:$ discount factor & 1.00 \\
$\quad \alpha:$ BJ exponent in utility & \\
Technology parameters: & 1.00 \\
$\quad y_{e}:$ market production, AD goods & 4.91 \\
$y_{u}:$ home production, AD goods & 1.00 \\
$\quad c:$ market transformation, AD to BJ & 15.7 \\
$\quad r$ home transformation, AD to BJ & \\
Labor market parameters: & 8.02 \\
$\quad \kappa:$ vacancy cost & .024 \\
$\delta:$ exogenous destruction rate & 1.24 \\
$\quad \phi:$ MP matching function parameter & .74 \\
$\quad \gamma:$ workers' bargaining power & .27 \\
Shopping parameters: & .02 \\
$\quad \psi_{u}:$ Probability unemployed search twice & \\
$\quad \psi_{e}:$ Probability employed search twice & \\
\hline
\end{tabular}


where $E_{R, u}$ denotes the semielasticity of the seller's revenues, which is given by

$$
E_{R, u}=\left[\frac{M E(u)+D E(u)+T E(u)}{1-M L T(u)}\right] \frac{1}{y_{e}+S^{*}(u)} .
$$

At the low unemployment steady state, the demand effect $D E$, which measures the decline in the seller's revenues caused by unemployed buyers spending less than employed buyers, is -16 percent of the seller's revenues, $y_{e}+S^{*}(u)$. The market power effect $M E$, which measures the decline in the seller's revenues due to unemployed buyers searching more and, hence, being less likely to be captive, is -33 percent of $y_{e}+$ $S^{*}(u)$. The tightness effect $T E$, which measures the increase in the seller's revenues due to higher unemployment increasing the tightness of the product market, is 6 percent of $y_{e}+S^{*}(u)$. The multiplier $1 /[1-$ $M L T(u)]$, which reflects the feedback between revenues and wages, is 2.7. Overall, the semielasticity of the seller's revenues with respect to unemployment is -1.15 and the semielasticity of the $J$-nullcline is -6 . Thus, if we increase unemployment from its lowest steady-state value of 5.3 percent to 10 percent, the $J$-nullcline falls by 28 percent, which is more than the decline required by the $u$-nullcline to obtain a second steady state.

The above calculations reveal that the key to multiplicity is the market power effect, not the demand effect. This surprising result follows almost directly from the targets of our calibration. In fact, the demand effect is proportional to the difference in expenditures between employed and unemployed workers, which is calibrated to be 15 percent of $y_{u}$. The market power effect is proportional to the expenditures of the unemployed workers, $y_{u}$, times the difference between the probability that an employed buyer is captive and the probability that an unemployed buyer is captive. Since the search intensity of employed workers, $1+\psi_{e}$, is 1.02 and the search intensity of unemployed workers, $1+\psi_{u}$, is calibrated to be 25 percent larger, the difference in the probability that employed and unemployed buyers are captive is 36 percent. Thus, the market power effect is proportional to 36 percent of $y_{u}$, which is more than twice as large as the demand effect. When the demand and the market power effects are put together, the model behaves as if unemployed workers had $36+15=51$ percent lower expenditures than employed workers, a difference so large that it is not surprising that multiplicity arises.

The market power effect captures the impact of unemployment on the competitiveness of the product market. For a seller posting the reservation price $r$, the market power effect manifests itself in a decline in 
the probability of meeting a captive buyer and, hence, in the probability of making a sale. However, for sellers as a whole, the market power effect manifests itself as a decline in the equilibrium price distribution. Hence, one might wonder how a change in the fraction of unemployed buyerswho are calibrated to pay only 2 percent lower prices than employed buyers - can possibly put a strong downward pressure on equilibrium prices to generate a large market power effect. In order to answer this question, it is helpful to take a detour in auction theory.

Consider a first-price procurement auction with symmetric information. In this auction, a seller submits a bid to a buyer knowing the number of sellers who are bidding for that buyer. The equilibrium in this auction is such that the seller bids the reservation price $r$ if the buyer is in contact with no other seller (i.e., captive), and it bids the opportunity cost $c$ if the buyer is in contact with other sellers (i.e., noncaptive). Since unemployed buyers are much more likely to be in contact with multiple sellers than employed buyers and since the difference between $r$ and $c$ is large (as implied by the data on price dispersion), an increase in unemployment causes a large decline in the seller's revenues. Note that, in this auction, unemployed buyers would pay much lower prices than employed buyers. The BJ market operates as a first-price procurement auction with asymmetric information. In this auction, a seller submits a bid to a buyer without knowing the number of sellers who are in contact with the buyer. The expected revenues for a seller under asymmetric information are the same as under symmetric information and, hence, are very sensitive to changes in unemployment. But equilibrium prices under asymmetric information are different, as sellers cannot discriminate between captive and noncaptive buyers. In particular, under asymmetric information, part of the gains from trade that are extracted by the noncaptive buyers from the sellers are "stolen" by the captive buyers as informational rents. For this reason, although unemployed buyers are worth much less to sellers than employed buyers, they pay only slightly lower prices.

\section{Validation}

We have shown that our model generates multiple equilibria for empirically relevant values of the parameters, that is, parameters chosen so as to match the observed differences in the shopping behavior of employed and unemployed workers and the rates at which workers transit between employment and unemployment. Now, we want to convince the reader of the empirical relevance of our model by providing some direct evidence in support of its two central mechanisms.

The first mechanism that is central to our model links unemployment, competition, and prices. When unemployment is higher, the product market becomes more competitive as buyers have more time to shop 
around. In turn, when the product market becomes more competitive, sellers have an incentive to lower their prices. Hence, the mechanism predicts that the consumer price index (CPI) should be lower when the unemployment rate is higher. Naturally, we should not expect this relationship to hold exactly in the data, as several variables may change at the same time as the unemployment rate (e.g., money supply and the dollar price of the $\mathrm{AD}$ good, productivity). Yet, as long as the changes in these variables are not too large, we should still see a negative relationship between the consumer price level and the unemployment rate. Figure $3 A$ plots the cyclical component of the CPI, the unemployment rate, and the employment rate over the period 1987-2011. Clearly, the cyclical component of the CPI moves in the opposite direction of the unemployment rate and in the same direction as the employment rate. This comovement is rather strong during the last 15 years and, in particular, during the Great Recession, a fact that is remarkable considering that the Federal Reserve Bank has followed a very expansionary monetary policy since 2008.

The mechanism linking unemployment, competition, and prices also predicts that price dispersion should be higher when the unemployment rate is higher. Intuitively, when unemployment is higher, the product market becomes more competitive and, while the most expensive sellers in the market still post the monopoly price $r$, the cheapest sellers in the market find it optimal to move their price closer to the competitive level $c$. Again, we should not expect this relationship to hold exactly in the data. Yet, as long as changes in variables other than unemployment are not too large, we should still see a positive relationship between the extent of price dispersion and the unemployment rate. Figure $3 B$ plots the unemployment rate and the average standard deviation of prices over the period 2004-9, which is the period covered by the KNCPD. In the period preceding the Great Recession, the unemployment rate slowly declined and so did the standard deviation of prices. Between 2008 and 2009, the unemployment rate rapidly rose from 4.5 percent to 10 percent and the standard deviation of prices rapidly increased by 15 percent.

The second mechanism that is central to our model links revenues, entry, and labor demand. When expected revenues are higher, new firms have a stronger incentive to enter the product market and existing firms have a stronger incentive to scale up their presence in the product market (by, e.g., introducing new products or opening new outlets). Since firms need labor to both enter and expand, aggregate labor demand increases. Hence, the mechanism predicts a positive relationship between employment, the entry of new firms, and the introduction of new products. Indeed, Bilbiie, Ghironi, and Melitz (2012) show that the introduction of new products and the entry of new firms account for a sizable fraction of yearly manufacturing output in the United States 


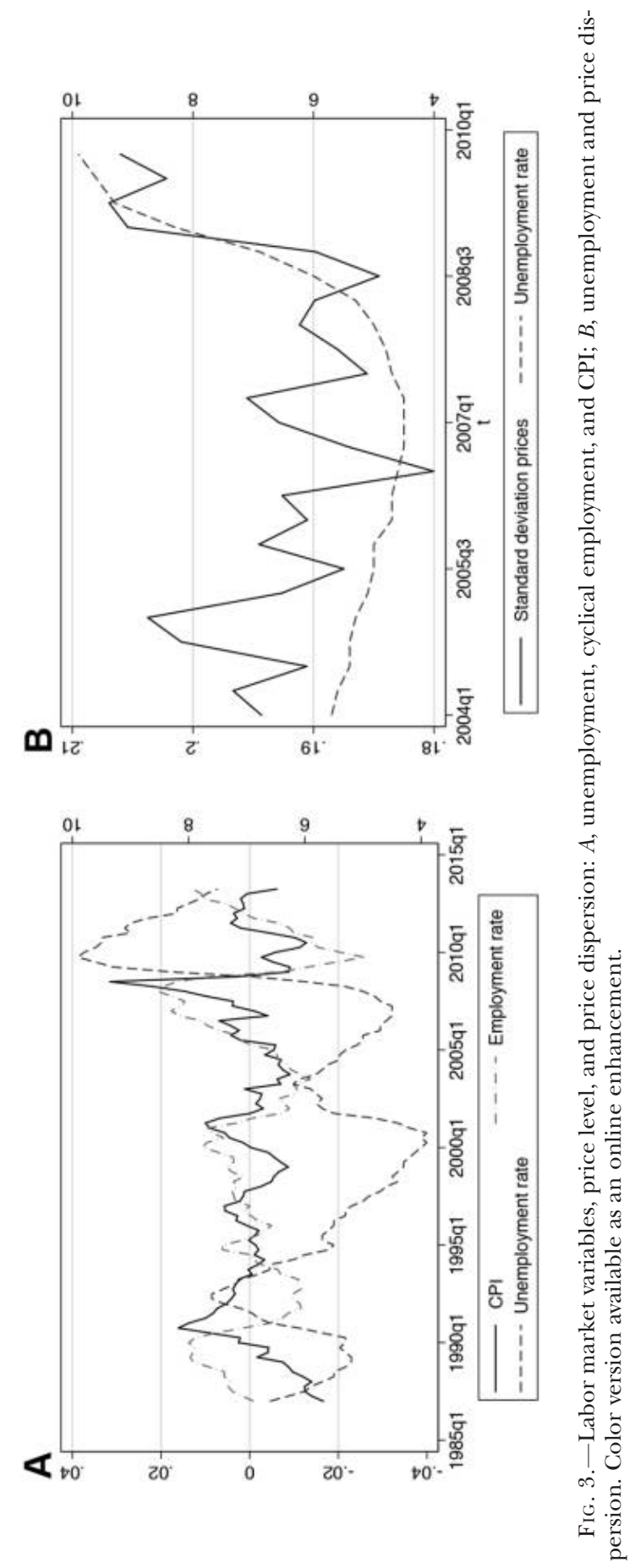

This content downloaded from 130.091.050.024 on May 04, 2016 07:33:16 AM

All use subject to University of Chicago Press Terms and Conditions (http://www.journals.uchicago.edu/t-and-c). 
and that this fraction is strongly procyclical and, hence, strongly positively correlated with employment.

\section{Expectation Shocks}

When calibrated to the US economy, the model features multiple equilibria. This suggests that observed fluctuations in the US labor market may be caused not only by changes in preferences, technologies, and other fundamentals but also by nonfundamental, self-fulfilling changes to the agents' expectations about future unemployment. In this section, we explore the qualitative and quantitative effects of an expectation shock. In Section V.A, we develop a version of the model in which the agents' expectations about long-run unemployment follow a simple twostate Markov switching process. In Section V.B, we use the augmented model to measure the effect of a negative shock to the agents' expectations about long-run unemployment. We find that, in response to the shock, the unemployment rate almost doubles, the tightness of the labor market falls by approximately 70 percent, the equity value of firms declines by almost 30 percent, and these changes take place without any concurrent decline in the real productivity of labor. We also find that the decline in the equity value of firms leads the rise in unemployment.

\section{A. Modeling Expectation Shocks}

We consider a version of the model in which the expectations of the agents about long-run unemployment follow a two-state Markov process. In the optimistic state, $G$, agents expect the economy to converge to the steady state with the lowest unemployment rate (conditional on remaining in the optimistic state). In the pessimistic state, $B$, agents expect the economy to converge to the steady state with the intermediate unemployment rate (conditional on remaining in the pessimistic state). The agents' expectations switch from optimistic to pessimistic at the Poisson rate $\pi_{G B}$, in which case the value of a worker to a firm jumps by $D_{G B}(u, J)$. Similarly, the agents' expectations switch from pessimistic to optimistic at the Poisson rate $\pi_{B G}$, in which case the value of a worker to a firm jumps by $D_{B G}(u, J)$.

In the optimistic state, the evolution of the economy is described by the following pair of differential equations:

$$
\begin{gathered}
\dot{\circ}_{t}=-u_{t} \lambda\left(\theta\left(J_{t}\right)\right)+\left(1-u_{t}\right) \delta \\
(\rho+\delta) J_{t}=(1-\gamma)\left[S^{*}\left(u_{t}\right)+y_{e}-y_{u}\right]+\stackrel{\circ}{J}_{t}+\pi_{G B} D_{G B}\left(u_{t}, J_{t}\right) .
\end{gathered}
$$


The first differential equation describes the evolution of unemployment. The second differential equation describes the evolution of the value of a worker to a firm. The equation states that the annuitized value of a worker is equal to the sum of three terms. The first term is the flow of revenues generated by the firm-worker pair and accruing to the firm. The second term is the change in the value of a worker conditional on the economy remaining in the optimistic state. The last term is the rate at which the economy switches to the pessimistic state, $\pi_{G B}$, times the change in the value of a worker conditional on the economy switching states, $D_{G B}\left(u_{t}, J_{t}\right)$. We denote as $\left\{E_{1}^{G}, E_{2}^{G}, E_{3}^{G}\right\}$ the steady states associated with the optimistic state and with $J_{G, 1}^{S}$ the stable manifold associated with the steady state with the lowest unemployment rate (see fig. 4).

In the pessimistic state, the evolution of the economy is described by the following pair of differential equations:

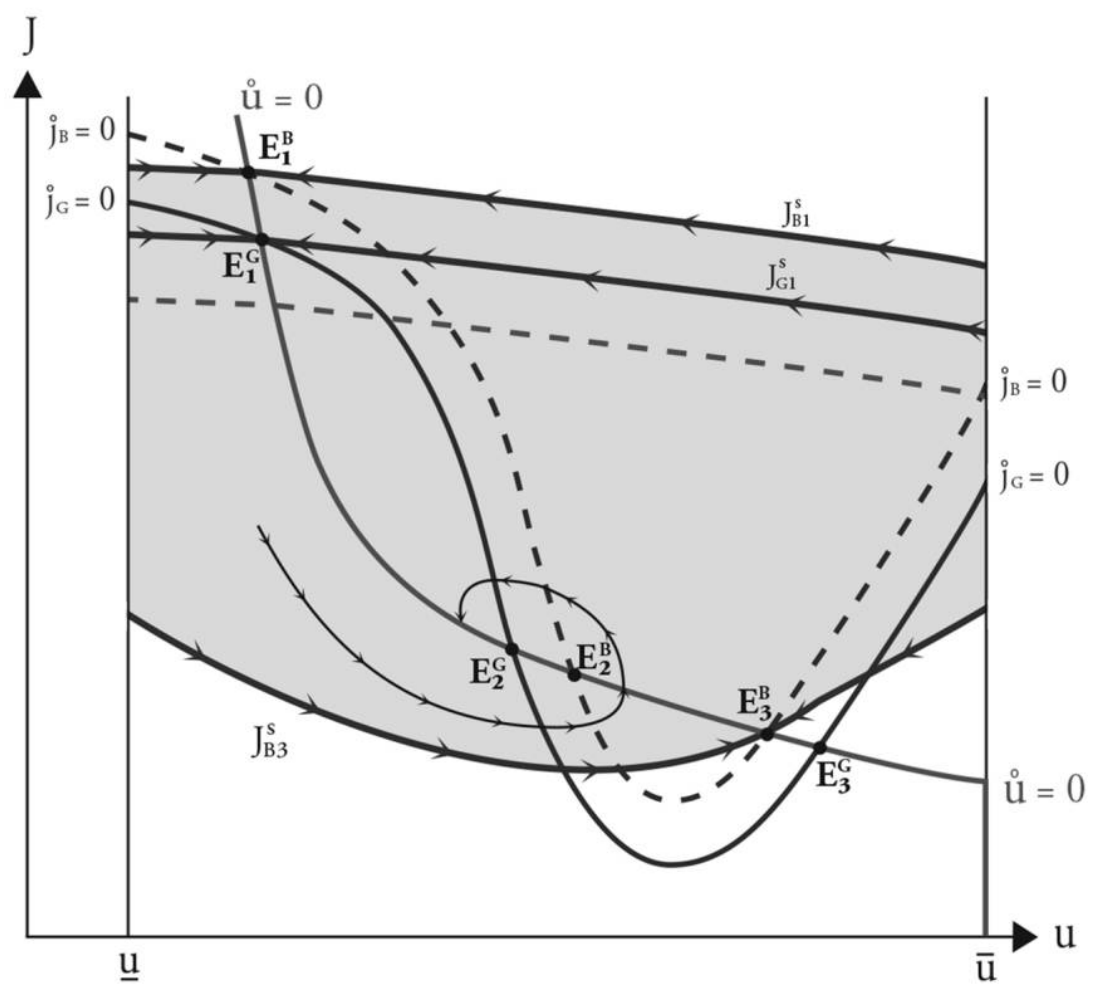

FIG. 4.-Expectation shocks. Color version available as an online enhancement. 
OOO

$$
\begin{gathered}
\stackrel{\circ}{t}_{t}=-u_{t} \lambda\left(\theta\left(J_{t}\right)\right)+\left(1-u_{t}\right) \delta \\
(\rho+\delta) J_{t}=(1-\gamma)\left[S^{*}\left(u_{t}\right)+y_{e}-y_{u}\right]+\stackrel{\circ}{J}_{t}+\pi_{B G} D_{B G}\left(u_{t}, J_{t}\right) .
\end{gathered}
$$

The first differential equation describes the evolution of unemployment, which is the same as in the optimistic state. The second differential equation describes the evolution of the value of a worker to a firm. The first two terms in this equation are the same as in the optimistic state. The last term is the rate at which the economy switches to the optimistic state, $\pi_{B G}$, times the change in the value of a worker conditional on the economy switching states, $D_{B G}\left(u_{t}, J_{t}\right)$. We denote as $\left\{E_{1}^{B}, E_{2}^{B}, E_{3}^{B}\right\}$ the steady states associated with the pessimistic state and with $J_{B, 2}^{S}$ the basin of attraction of the intermediate steady state (see fig. 4).

The expectations of the agents must be rational. First, when the economy switches from the optimistic to the pessimistic state, the value of a worker to a firm must fall in the basin of attraction $J_{B, 2}^{S}$ of the intermediate steady state $E_{2}^{B}$. This condition guarantees that, if the economy remains in the pessimistic state forever after, it will converge to $E_{2}^{B}$. Second, when the economy switches from the pessimistic to the optimistic state, the value of a worker to a firm must land on the stable manifold $J_{G, 1}^{S}$ associated with the low-unemployment steady state $E_{1}^{G}$. This condition guarantees that, if the economy remains in the optimistic state forever after, it will converge to $E_{1}^{G}$. Finally, the initial value of a worker to a firm must be on the stable manifold associated with $E_{1}^{G}$ if the initial state of the economy is optimistic, and it must belong to the basin of attraction of $E_{2}^{B}$ if the initial state of the economy is pessimistic.

We are now in the position to formally define an equilibrium. Let $h$ denote a history of realizations of the two-state Markov process for the agents' expectations and $t_{n}(h)$ the $n$th time at which the state of the process switches in history $h$. Then we have the following definition.

Definition 3. A Markov switching rational expectation equilibrium is a history-dependent path $\left\{u_{t}(h), J_{t}(h)\right\}$ such that, for every $h$, the following conditions are satisfied: (i) For all $t \in\left[t_{n}, t_{n+1}\right)$ with $h_{t_{n}}=G,\left\{u_{t}, J_{t}\right\}$ satisfies (23)-(24). (ii) For all $t \in\left[t_{n}, t_{n+1}\right)$ with $h_{t_{n}}=B,\left\{u_{t}, J_{t}\right\}$ satisfies (25)-(26). (iii) For any $u \in[\underline{u}, \bar{u}]$ and any $J \in J_{G, 1}^{S}(u), J+D_{G B}(u, J) \in J_{B, 2}^{S}(u)$. For any $u \in[\underline{u}, \bar{u}]$ and any $J \in J_{B, 2}^{S}(u), J+D_{B G}(u, J) \in J_{G, 1}^{S}(u)$. (iv) $J_{0} \in J_{G, 1}^{S}\left(u_{0}\right)$ if $h_{0}=G$, and $J_{0} \in J_{B, 2}^{S}\left(u_{0}\right)$ if $h_{0}=B$.

Naturally, we could have specified any number of different stochastic processes for the agents' expectations about future unemployment. However, the one that we chose is the most natural and, arguably, the only one that has the potential to be empirically relevant. Indeed, shocks to the agents' expectations about the path that the economy will follow while converging to a given steady state are unlikely to be quantitatively important, as the transitional dynamics of the model are very fast. 
Hence, it is natural to focus on shocks to the agents' expectations about the steady state that the economy will reach. Second, notice that, according to our benchmark calibration, the high-unemployment steady state features no economic activity. For other reasonable calibrations, the high-unemployment steady state features some economic activity but still displays an unemployment rate much greater than anything observed in the history of the US economy. Hence, it is natural to focus on a stochastic process in which the agents expect to reach either the steady state with the lowest unemployment rate or the one with the intermediate unemployment rate. Finally, the assumption that the stochastic process is Markovian is made, as usual, for the sake of simplicity.

The stochastic process for the agents' expectations is fully characterized by the four variables $\left\{\pi_{G B}, \pi_{B G}, D_{G B}, D_{B G}\right\}$. The arrival rates $\pi_{G B}$ and $\pi_{B G}$ determine the average duration of the optimistic state and of the pessimistic state. The jump $D_{G B}$ determines the path that the economy will follow in reaching the pessimistic steady state. The jump $D_{B G}$ is actually not a free variable because there is only one path (i.e., the stable manifold $\left.J_{G, 1}^{S}\right)$ that leads to the optimistic steady state and, hence, $D_{B G}(u, J)$ must be equal to $J_{G, 1}^{S}(u)-J$. Armed with a version of the model that allows for shocks to technology, preferences, and expectations, one could estimate the values for $\pi_{G B}, \pi_{B G}$, and $D_{G B}$ using time-series data on unemployment, vacancies, productivity, and the stock market. This estimation would be well beyond the scope of this paper. Here we simply take the view that negative expectation shocks are rather rare and persistent events associated with a large decline in the value of firms. In particular, we choose $\pi_{G B}$ so that a negative expectation shock occurs, on average, once every 50 years; we choose $\pi_{B G}$ so that the shock lasts, on average, 15 years; and we choose $D_{G B}$ so that, when the shock hits the economy, the value of the firms falls by 20 percent. ${ }^{13}$

\section{B. Response to a Negative Expectation Shock}

Figure 5 reports the behavior of unemployment, labor market tightness, labor productivity, and the value of the firm when the economy is at the optimistic steady state and the agents' expectation about future unemployment become pessimistic. Panel $A$ plots the response of the unemployment rate, measured as a percentage deviation from its value at the optimistic steady state. The unemployment rate increases by 120 per-

\footnotetext{
${ }^{13}$ The response of the economy to a negative expectation shock is not very sensitive to the choice of these particular calibration targets. Indeed, the behavior of the model is driven by changes in the value of an additional worker to a firm. Since worker-firm relationships are, on average, relatively short (i.e., they last approximately 4 years), it does not matter much whether a switch in expectations occurs, on average, once every 15, 20, or 50 years.
} 
A

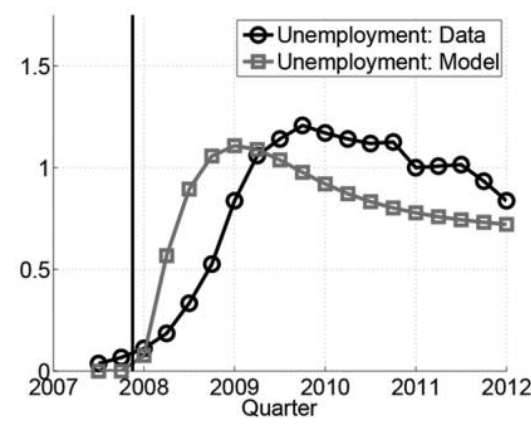

C

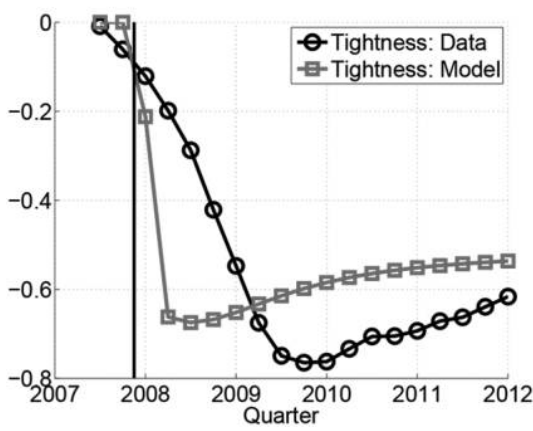

B

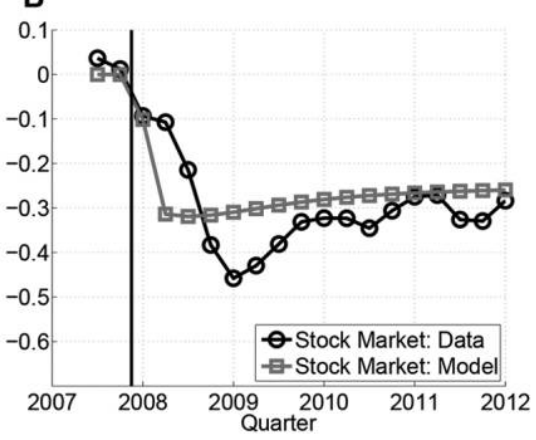

D

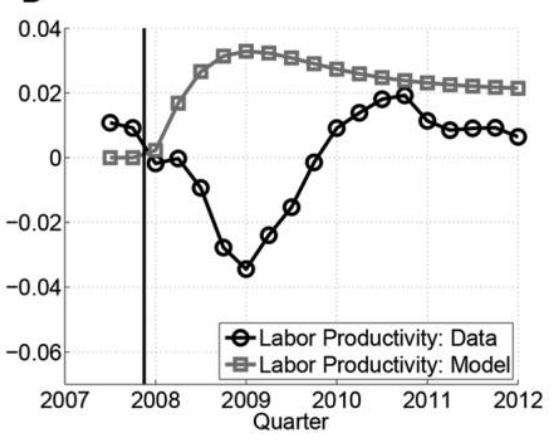

FIG. 5.- Response to a negative expectation shock: $A$, unemployment: deviation from 2007:Q1; $B$, stock market: deviation from trend; $C$, tightness: deviation from 2007:Q1; $D$, labor productivity: deviation from trend. Color version available as an online enhancement.

cent during the first six quarters after the economy is hit by the negative shock. After reaching its peak, the unemployment rate begins a slow decline toward the pessimistic steady state, where its value is approximately 80 percent higher than at the optimistic steady state. This illustrates the first key feature of a negative expectation shock: it causes an increase in unemployment that is very large relative to, say, the one caused by a productivity shock (see, e.g., Shimer 2005).

Panel $B$ plots the response of the stock market value of an active firm, measured as a percentage deviation from its value at the optimistic steady state. The value of an active firm in the stock market, $V$, is equal to the value of the firm, $J$, net of the repayment of the firm's debt, $D$. Under the assumption that $D$ is a constant fraction $d=1 / 3$ of the value of the firm at the optimistic steady state, $J_{G, 1}^{*}$, this implies that $V$ is equal to $J-$ $d J_{G, 1}^{*} \cdot{ }^{14}$ As one can see from panel $B$, when the economy is hit by the neg-

${ }^{14}$ Over the period 1987-2007, the average ratio of credit market debt to net worth in the nonfinancial corporate business sector was approximately 50 percent, i.e., $d /(1-d)=1 / 2$, which implies $d=1 / 3$. 
ative shock, the stock market value of a firm falls instantly by 30 percent. Then, the stock market value of a firm begins a slow and modest rise toward the pessimistic steady state, where its value is approximately 25 percent lower than at the optimistic steady state. Figure 6 is a scatter plot of unemployment and the stock market value of a firm. In this picture, one can clearly see the second key feature of a negative expectation shock: the decline in the stock market takes place before the increase in unemployment, as the value responds instantaneously to the change in expectations about future unemployment, revenues, and profits, while the expected increase in unemployment takes some time to materialize.

Panel $C$ of figure 5 plots the response of labor market tightness (i.e., the vacancy-to-unemployment ratio), measured as a percentage deviation from its value at the optimistic steady state. When the economy is hit by a negative shock, the tightness of the labor market falls by approximately 70 percent. Then it begins a slow increase toward the pessimistic steady state, where its value is 60 percent lower than at the optimistic steady state. The tightness of the labor market behaves exactly like the value of an active firm, and hence, its decline precedes the increase in unemployment. This finding is not surprising as the tightness of the labor market is determined by the value of an active firm through the freeentry condition.

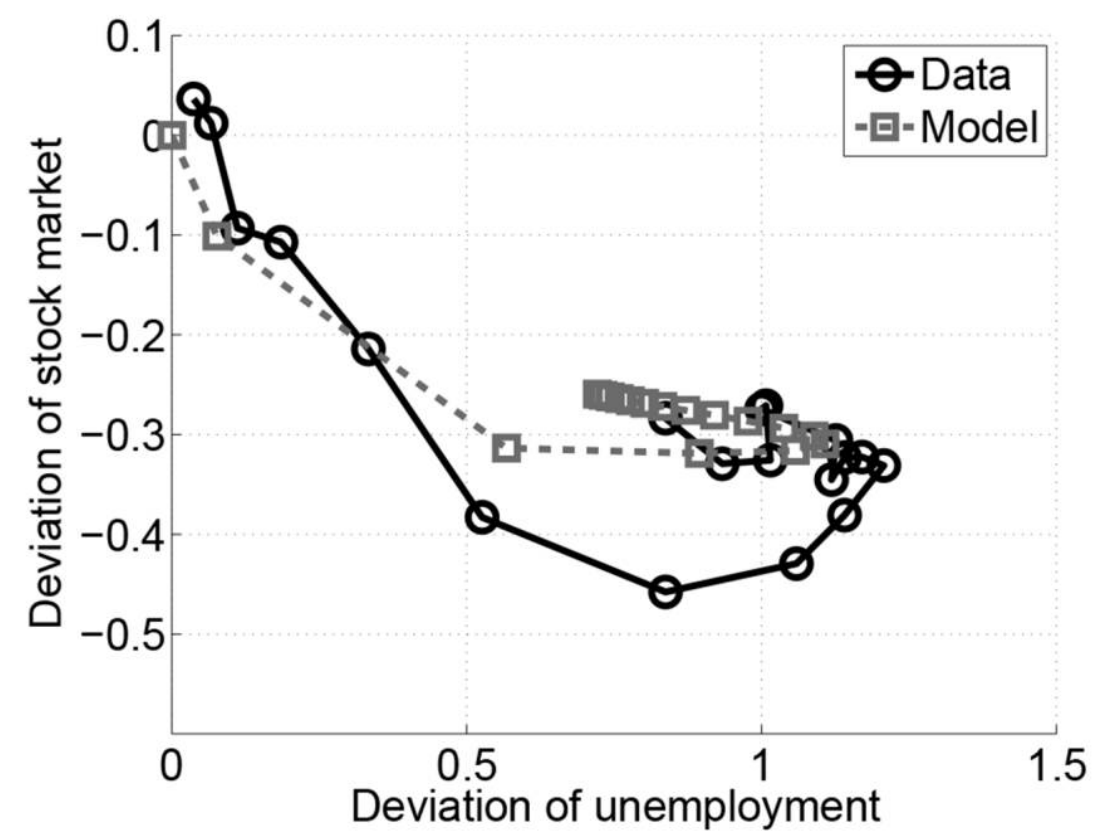

FIG. 6.-Unemployment rate and stock market. Color version available as an online enhancement. 
Panel $D$ of figure 5 plots the response of real labor productivity, measured as a percentage deviation from its value at the optimistic steady state. We define real labor productivity as the ratio between nominal labor productivity and the CPI. Nominal labor productivity is given by the revenues generated by each employed worker $S^{*}(u)+y_{e}$. The CPI is given by $Q_{B J}^{*} P_{B J}(u)+Q_{A D}^{*} P_{A D}(u)$, where $Q_{B J}^{*}$ and $Q_{A D}^{*}$ are the quantities of the $\mathrm{BJ}$ and $\mathrm{AD}$ goods sold at the optimistic steady state and $P_{B J}(u)$ and $P_{A D}(u)$ are the average prices at which the $\mathrm{BJ}$ and $\mathrm{AD}$ goods are sold when the unemployment rate is $u$. As one can see from panel $D$, the response of real labor productivity to a negative expectation shock is very small compared to the response of the other variables. This finding is surprising but easy to understand. Nominal labor productivity (the seller's revenues) declines substantially in response to the negative expectation shock. However, the decline in nominal labor productivity takes place mostly because of a decline in prices and not because of a decline in quantities. Therefore, when we deflate nominal labor productivity, we find that real labor productivity does not change much and, indeed, the small change in real labor productivity is positive. This is the third key feature of a negative expectation shock: the large increase in unemployment and the large decline in the value of a firm take place while real labor productivity remains approximately constant.

During the Great Recession and its aftermath, the US economy displayed the same features that characterize the response to a negative expectation shock. First, the unemployment rate more than doubled between the last quarter of 2007 and the second quarter of 2009, and since then, it has remained at a level substantially higher than before the beginning of the recession. Second, the stock market fell 40 percent below trend during 2008, and its decline preceded the bulk of the increase in the unemployment rate. Third, real labor productivity fell below trend by only a few percentage points during the recession and was already back on trend by the second quarter of 2009, a time when the unemployment rate was still twice as high as before the recession. Fourth, as discussed in Section IV, prices fell and price dispersion increased during the Great Recession. Figure 6 overlays the behavior of the US economy from 2007 to 2012 and the response of the model economy to a negative expectation shock. From this figure, it is clear that the behavior of the US economy during this period is not only qualitatively but also quantitatively rather similar to the response to a negative expectation shock.

The above observations suggest the possibility that the fundamental shocks to the financial and housing sectors that have ushered in and, presumably, started the Great Recession may have affected the economy not only directly but also indirectly by triggering a nonfundamental 
change in the agents' expectations about long-run unemployment. This hypothesis would explain why labor market variables responded so strongly to fundamental shocks that had a rather small impact on labor productivity. Moreover, this hypothesis would explain why the labor market is still sluggish several years after any effect of the fundamental shocks on labor productivity has disappeared.

\section{Conclusions}

The paper advances a novel theory of self-fulfilling unemployment fluctuations. According to our theory, when unemployment is higher, firms' revenues are lower because unemployed buyers spend less income and devote more time looking for low prices than employed buyers. In turn, when revenues are lower, new firms are less inclined to enter the product market and existing firms are less inclined to expand their presence in the product market, and, hence, labor demand is lower and fewer vacancies are created. In the theoretical part of the paper, we prove that the feedback loop between unemployment, prices, and demand can generate multiple equilibria if the differences between employed and unemployed buyers in either expenditures or shopping time are sufficiently large. In the empirical part of the paper, we show that the observed differences in the shopping behavior of employed and unemployed buyers are indeed strong enough to generate multiplicity. Surprisingly, we find that the firms' revenues are very sensitive to the unemployment rate mainly because of the difference in the amount of time spent shopping by employed and unemployed buyers and not so much because of the difference in their expenditures. In the last part of the paper, we show that, owing to the presence of multiple equilibria, the economy may fluctuate not only because of shocks to technology, preferences, or other fundamentals but also because of self-fulfilling shocks to the agents' expectations about future unemployment. We find that the response of the economy to a negative expectation shock about long-run unemployment has three distinctive features: (i) a large and persistent increase in unemployment, (ii) a large decline in the equity value of firms, which precedes the increase in unemployment, and (iii) relatively small fluctuations in the real productivity of labor.

\section{Appendix A}

\section{Proof of Lemma 1}

Let $F$ denote an arbitrary distribution of prices for the $\mathrm{BJ}$ good. Let $\mathcal{F}$ denote the support of the distribution $F$ and let $\xi(p)$ denote the measure of prices equal 
to $p$ in the distribution $F$. Given $F$, the expected revenues for a seller are given by $S(p)+y_{e}$, where $p$ denotes the price of the BJ good posted by the seller, $S(p)$ denotes the revenues from sales in the $\mathrm{BJ}$ market net of the opportunity cost of producing the $\mathrm{BJ}$ good, and $y_{e}$ are the revenues from sales in the $\mathrm{AD}$ market plus the opportunity cost of producing the BJ good. Formally, the seller's net revenues in the BJ market are

$$
\begin{aligned}
S(p)= & \mu(\sigma) \frac{u\left(1+\psi_{u}\right)}{b}\left\{1-\frac{2 \psi_{u} \nu(\sigma)[F(p)-\xi(p) / 2]}{1+\psi_{u}}\right\} \frac{\alpha y_{u}(p-c)}{p} \\
& +\mu(\sigma) \frac{(1-u)\left(1+\psi_{e}\right)}{b}\left\{1-\frac{2 \psi_{e} \nu(\sigma)[F(p)-\xi(p) / 2]}{1+\psi_{e}}\right\} \frac{\alpha w(p-c)}{p} .
\end{aligned}
$$

Note that (A1) assumes that a buyer meeting two sellers charging the price $p$ purchases from either seller with probability one-half. However, lemma 1 holds for any other tie-breaking rule.

A seller chooses the price $p$ for the BJ good so as to maximize its expected revenues, $S(p)+y_{e}$, or, equivalently, to maximize its net revenues in the BJ market, $S(p)$. Therefore, the price distribution $F$ is consistent with the seller's optimal pricing strategy if and only if

$$
\begin{aligned}
S\left(p_{0}\right) & =S^{*} \quad \text { for all } p_{0} \in \mathcal{F}, \\
S^{*} & \equiv \max _{p} S(p) .
\end{aligned}
$$

Claim 1. For any $F, S^{*}>0$.

Proof. For a seller posting the reservation price $r$, net revenues are

$$
\begin{aligned}
S(r) \geq & \mu(\sigma) \frac{u\left(1+\psi_{u}\right)}{b} \frac{1-\psi_{u}}{1+\psi_{u}} \frac{\alpha y_{u}(r-c)}{r} \\
& +\mu(\sigma)+\frac{(1-u)\left(1+\psi_{e}\right)}{b} \frac{1-\psi_{e}}{1+\psi_{e}} \frac{\alpha w(r-c)}{r}>0 .
\end{aligned}
$$

As $S^{*} \geq S(r)$ and $S(r)>0$, it follows that $S^{*}>0$. QED

Claim 2. If $F$ satisfies (A2), then $\mathcal{F}$ is continuous.

Proof. Suppose that there is a price $p_{0}$ such that $\xi\left(p_{0}\right)>0$. For a seller posting the price $p_{0}$, net revenues are

$$
\begin{aligned}
S\left(p_{0}\right)= & \mu(\sigma) \frac{u\left(1+\psi_{u}\right)}{b}\left\{1-\frac{2 \psi_{u} \nu(\sigma)\left[F\left(p_{0}\right)-\xi\left(p_{0}\right) / 2\right]}{1+\psi_{u}}\right\} \frac{\alpha y_{u}\left(p_{0}-c\right)}{p_{0}} \\
& +\mu(\sigma) \frac{(1-u)\left(1+\psi_{e}\right)}{b}\left\{1-\frac{2 \psi_{e} \nu(\sigma)\left[F\left(p_{0}\right)-\xi\left(p_{0}\right) / 2\right]}{1+\psi_{e}}\right\} \frac{\alpha w\left(p_{0}-c\right)}{p_{0}} .
\end{aligned}
$$

For a seller posting the price $p_{0}-\epsilon$, with $\epsilon>0$, net revenues are 


$$
\begin{aligned}
S\left(p_{0}-\epsilon\right) & =\mu(\sigma) \frac{u\left(1+\psi_{u}\right)}{b}\left\{1-\frac{2 \psi_{u} v(\sigma)\left[F\left(p_{0}-\epsilon\right)-\xi\left(p_{0}-\epsilon\right) / 2\right]}{1+\psi_{u}}\right\} \frac{\alpha y_{u}\left(p_{0}-\epsilon-c\right)}{p_{0}-\epsilon} \\
& +\mu(\sigma) \frac{(1-u)\left(1-\psi_{e}\right)}{b}\left\{1-\frac{2 \psi_{e} v(\sigma)\left[F\left(p_{0}-\epsilon\right)-\xi\left(p_{0}-\epsilon\right) / 2\right]}{1+\psi_{e}}\right\} \frac{\alpha w\left(p_{0}-\epsilon-c\right)}{p_{0}-\epsilon} \\
> & \mu(\sigma) \frac{u\left(1+\psi_{u}\right)}{b}\left\{1-\frac{2 \psi_{u} v(\sigma)\left[F\left(p_{0}\right)-\xi\left(p_{0}\right)\right]}{1+\psi_{u}}\right\} \frac{\alpha y_{u}\left(p_{0}-\epsilon-c\right)}{p_{0}-\epsilon} \\
& +\mu(\sigma) \frac{(1-u)\left(1-\psi_{e}\right)}{b}\left\{1-\frac{2 \psi_{e} v(\sigma)\left[F\left(p_{0}\right)-\xi\left(p_{0}\right)\right]}{1+\psi_{e}}\right\} \frac{\alpha w\left(p_{0}-\epsilon-c\right)}{p_{0}-\epsilon},
\end{aligned}
$$

where the above inequality follows from $F\left(p_{0}-\epsilon\right)-\xi\left(p_{0}-\epsilon\right) / 2 \leq F\left(p_{0}-\epsilon\right)$ and $F\left(p_{0}-\epsilon\right)<F\left(p_{0}\right)-\xi\left(p_{0}\right) / 2$. Since $p_{0} \in \mathcal{F}$, (A2) implies $S\left(p_{0}\right)=S^{*}>0$ and, hence, $p_{0}>c$. In turn, if $p_{0}>c$, there exists an $\epsilon$ small enough that $S\left(p_{0}\right)<$ $S\left(p_{0}-\epsilon\right)$. As $S\left(p_{0}-\epsilon\right) \leq S^{*}$ and $S\left(p_{0}\right)<S\left(p_{0}-\epsilon\right), S\left(p_{0}\right)<S^{*}$, which contradicts the hypothesis that $F$ satisfies (A2). QED

Claim 3. If $F$ satisfies (4), then $\bar{p}=r$.

Proof. Suppose that $\bar{p}<r$. For a seller posting the price $\bar{p}$, net revenues are

$$
\begin{aligned}
S(\bar{p})= & \mu(\sigma) \frac{u\left(1+\psi_{u}\right)}{b}\left[1-\frac{2 \psi_{u} \nu(\sigma)}{1+\psi_{u}}\right] \frac{\alpha y_{u}(\bar{p}-c)}{\bar{p}} \\
& +\mu(\sigma) \frac{(1-u)\left(1+\psi_{e}\right)}{b}\left[1-\frac{2 \psi_{e} \nu(\sigma)}{1+\psi_{e}}\right] \frac{\alpha w(\bar{p}-c)}{\bar{p}} .
\end{aligned}
$$

For a seller posting the price $r$, net revenues are

$$
\begin{aligned}
S(r)= & \mu(\sigma) \frac{u\left(1+\psi_{u}\right)}{b}\left[1-\frac{2 \psi_{u} \nu(\sigma)}{1+\psi_{u}}\right] \frac{\alpha y_{u}(r-c)}{r} \\
& +\mu(\sigma) \frac{(1-u)\left(1+\psi_{e}\right)}{b}\left[1-\frac{2 \psi_{e} \nu(\sigma)}{1+\psi_{e}}\right] \frac{\alpha w(r-c)}{r} .
\end{aligned}
$$

Clearly $S(\bar{p})<S(r) \leq S^{*}$, which contradicts the hypothesis that $F$ satisfies (A2). Next, suppose that $\bar{p}>r$. In this case, the net revenues for a seller posting the price $\bar{p}$ are $S(\bar{p})=0$. The net revenues for a seller posting the price $r$ are $S(r)>$ 0 . Hence $S(\bar{p})<S(r) \leq S^{*}$, which contradicts the hypothesis that $F$ satisfies (A2). Having ruled out $\bar{p}<r$ and $\bar{p}>r$, it follows that $\bar{p}=r$. QED

Claim 4. If $F$ satisfies (A2), then $\mathcal{F}$ is connected.

Proof. Suppose that $\mathcal{F}$ is not connected; that is, there exist $p_{0}, p_{1} \in \mathcal{F}$, such that $p_{0}<p_{1}$ and $F\left(p_{0}\right)=F\left(p_{1}\right)$. For a seller posting the price $p_{0}$, net revenues are

$$
\begin{aligned}
S\left(p_{0}\right)= & \mu(\sigma) \frac{u\left(1+\psi_{u}\right)}{b}\left[1-\frac{2 \psi_{u} \nu(\sigma) F\left(p_{0}\right)}{1+\psi_{u}}\right] \frac{\alpha y_{u}\left(p_{0}-c\right)}{p_{0}} \\
& +\mu(\sigma) \frac{(1-u)\left(1+\psi_{e}\right)}{b}\left[1-\frac{2 \psi_{e} \nu(\sigma) F\left(p_{0}\right)}{1+\psi_{e}}\right] \frac{\alpha w\left(p_{0}-c\right)}{p_{0}} .
\end{aligned}
$$

For a seller posting the price $p_{1}$, net revenues are 


$$
\begin{aligned}
S\left(p_{1}\right)= & \mu(\sigma) \frac{u\left(1+\psi_{u}\right)}{b}\left[1-\frac{2 \psi_{u} \nu(\sigma) F\left(p_{0}\right)}{1+\psi_{u}}\right] \frac{\alpha y_{u}\left(p_{1}-c\right)}{p_{1}} \\
& +\mu(\sigma) \frac{(1-u)\left(1+\psi_{e}\right)}{b}\left[1-\frac{2 \psi_{e} \nu(\sigma) F\left(p_{0}\right)}{1+\psi_{e}}\right] \frac{\alpha w\left(p_{1}-c\right)}{p_{1}} .
\end{aligned}
$$

Clearly $S\left(p_{0}\right)<S\left(p_{1}\right) \leq S^{*}$, which contradicts the hypothesis that $F$ satisfies (A2). QED

Claim 5. F satisfies (A2) if and only if

$$
\begin{aligned}
F(p)= & \left(u\left(1+\psi_{u}\right)\left\{1-\left[1-\frac{2 \psi_{u} \nu(\sigma)}{1+\psi_{u}}\right] \frac{(r-c) p}{(p-c) r}\right\} y_{u}\right. \\
& \left.+(1-u)\left(1+\psi_{e}\right)\left\{1-\left[1-\frac{2 \psi_{e} \nu(\sigma)}{1+\psi_{e}}\right] \frac{(r-c) p}{(p-c) r}\right\} w\right) \\
& \div 2 \nu(\sigma)\left[u \psi_{u} y_{u}+(1-u) \psi_{e} w\right] .
\end{aligned}
$$

Proof. First, suppose $F$ satisfies (A2). Claim 3 implies that $S(r)=S^{*}$ and claim 4 implies that $S(p)=S^{*}$ for all $p \in[p, r]$, with $p \in(c, r)$. Thus, $S(p)=S(r)$ for all $p \in[p, r]$. The solution to the equation $S(p)=S(r)$ with respect to $F(p)$ is (A3). Conversely, suppose that $F$ is given by (A3) for all $p \in[p, \bar{p}]$, with $\bar{p}=r$ and $p$ such that $F(p)=0$. Given $F$, it is easy to verify that $S(p)^{-}=S^{*}>0$ for all $p \in[\bar{p}, \bar{p}], S(p)<S^{*}$ for all $p \notin[p, \bar{p}]$, where $S^{*} \equiv S(r)$. Hence, $F$ satisfies (A2). QED

\section{Appendix B}

\section{Continuous Time Limit}

Let $\Delta \in(0,1]$ denote the length of a period. A worker has preferences described by the utility function $\sum_{i=0}^{\infty} e^{-\rho \Delta i} x^{\alpha}(\Delta i)^{\alpha} y(\Delta i)^{1-\alpha}$, where $x(\Delta i)$ denotes consumption of the $\mathrm{BJ}$ good and $y(\Delta i)$ denotes consumption of the $\mathrm{AD}$ good in period $i$. In period $i$, a worker has an income of $y_{u} \Delta$ units of the $\mathrm{AD}$ good if he is unemployed and an income of $w_{\Delta}(u(\Delta i))$ units of the $\mathrm{AD}$ good if he is employed, where $u(\Delta i)$ denotes the unemployment rate. A firm has preferences described by the utility function $\sum_{i=0}^{\infty} e^{-\rho \Delta i} y(\Delta i)-k \Delta v(\Delta i)$, where $y(\Delta i)$ denotes consumption of the $\mathrm{AD}$ good and $v(\Delta i)$ denotes the number of vacancies created in the MP market. In period $i$, every worker employed by the firm is able to produce any combination of $\mathrm{AD}$ and $\mathrm{BJ}$ goods such that $c x+y=y_{e} \Delta$.

Consider the economy at some arbitrary date $t=i \Delta$. In the MP market, unemployed workers, $u(t-\Delta)$, and vacant jobs, $v(t)$, create $M(u(t-\Delta), v(t)) \Delta$ matches. Hence, an unemployed worker meets a vacant job with probability $\lambda(\theta(t)) \Delta$ and a vacant job meets an unemployed worker with probability $\eta(\theta(t)) \Delta$, where $\theta(t)=v(t) / u(t-\Delta)$. In the MP market, existing firm-worker matches are destroyed with an exogenous probability $1-e^{-\delta \Delta}$. In the BJ market, an unemployed buyer searches for a seller once with probability $1-\psi_{u}$ and twice with probability $\psi_{u}$. Similarly, an employed buyer searches once with probability $1-\psi_{e}$ and twice with probability $\psi_{e}$. A buyer's searches, $b(u(t))=u(t)\left(1+\psi_{u}\right)+[1-u(t)](1+$ 
$\left.\psi_{e}\right)$, and a seller's, $s(u(t))=1-u(t)$, create $N(b(u(t)), s(u(t)))$ matches. Hence, a buyer's search matches with a seller with probability $\nu(\sigma(t))$ and a seller matches with a buyer with probability $\mu(\sigma(t))$, where $\sigma(t)=s(t) / b(t)$.

It is straightforward to verify that the seller's net revenues in the BJ market are

$$
\begin{aligned}
S_{\Delta}^{*}(u(t))= & \mu(\sigma(u(t))) \frac{u\left(1+\psi_{u}\right)}{b(u(t))}\left[1-\frac{2 \psi_{u} \nu(\sigma(u(t)))}{1+\psi_{u}}\right] \frac{r-c}{r} \alpha y_{u} \Delta \\
& +\mu(\sigma(u(t))) \frac{[1-u(t)]\left(1+\psi_{e}\right)}{b(u(t))}\left[1-\frac{2 \psi_{e} \nu(\sigma(u(t)))}{1+\psi_{e}}\right] \frac{r-c}{r} \alpha w_{\Delta}(u(t)),
\end{aligned}
$$

where

$$
w_{\Delta}(u(t))=y_{u} \Delta+\gamma\left[S_{\Delta}^{*}(u(t))+y_{e} \Delta-y_{u} \Delta\right] .
$$

Similarly, it is straightforward to verify that the tightness $\theta(t)$ of the MP market is

$$
\theta_{\Delta}(J)=\eta^{-1}\left(\min \left\{\frac{k \Delta}{J \Delta}, 1\right\}\right)
$$

The Bellman equation for the value of an additional worker to a firm is

$$
\begin{aligned}
J(t) & =(1-\gamma)\left[S^{*}(u(t), \Delta)+y_{e} \Delta-y_{u} \Delta\right]+e^{-(\rho+\delta) \Delta} J(t+\Delta) \\
& =(1-\gamma)\left[S^{*}(u(t))+y_{e}-y_{u}\right] \Delta+e^{-(\rho+\delta) \Delta} J(t+\Delta),
\end{aligned}
$$

where the second line makes use of the fact that $S_{\Delta}^{*}(u(t))=S^{*}(u(t))$ and $w_{\Delta}(u(t))=\Delta w(u(t))$, with $S^{*}(u)$ and $w^{*}(u)$ defined as in (6) and (7). The law of motion for unemployment is

$$
\begin{aligned}
u(t) & =u(t-\Delta)[1-\lambda(\theta(J(t), \Delta)) \Delta]+[1-u(t)]\left(1-e^{-\delta \Delta}\right) \\
& =u(t-\Delta)\left[1-\lambda\left(\theta\left(J_{t}\right)\right) \Delta\right]+[1-u(t)]\left(1-e^{-\delta \Delta}\right),
\end{aligned}
$$

where the second line makes use of the fact that $\theta_{\Delta}(J)=\theta(J)$, with $\theta(J)$ defined as in (8). The limit for $\Delta \rightarrow 0$ of the difference equation (B4) is the differential equation (12). Similarly, the limit for $\Delta \rightarrow 0$ of the difference equation (B5) is the differential equation (13). QED

\section{Appendix C}

\section{Proof of Theorem 1}

Proof of parts i and ii: Given $u \in[\underline{u}, \bar{u}]$ and $y_{e} \geq y_{u}$, the seller's net revenues in the BJ market are

$$
\begin{aligned}
S^{*}\left(u, y_{e}\right)= & \frac{\alpha(r-c)}{r}\left\{\frac{u\left(1+\psi_{u}\right)}{b(u)}\left[1-\frac{2 \psi_{u}}{1+\psi_{u}} \frac{1-u}{b(u)}\right] y_{u}\right. \\
& \left.+\frac{(1-u)\left(1+\psi_{e}\right)}{b(u)}\left[1-\frac{2 \psi_{e}}{1+\psi_{e}} \frac{1-u}{b(u)}\right] w^{*}\left(u, y_{e}\right)\right\}
\end{aligned}
$$


where

$$
w^{*}\left(u, y_{e}\right)=y_{u}+\gamma\left[S^{*}\left(u, y_{e}\right)+y_{e}-y_{u}\right]
$$

The derivative of $S^{*}\left(u, y_{e}\right)$ with respect to $u$ has the same sign as

$$
\begin{aligned}
\Sigma_{u}\left(u, y_{e}\right)= & \frac{\left(1+\psi_{u}\right)\left(1+\psi_{e}\right)}{b(u)^{2}}\left\{\left[1-\frac{2 \psi_{u}}{1+\psi_{u}} \frac{1-u}{b(u)}\right] y_{u}\right. \\
& \left.-\left[1-\frac{2 \psi_{e}}{1+\psi_{e}} \frac{1-u}{b(u)}\right] w(u)\right\}+2 \frac{1+\psi_{u}}{b(u)^{2}} \\
& \times\left[\frac{\left(1+\psi_{u}\right) u}{b(u)} \frac{\psi_{u}}{1+\psi_{u}} y_{u}+\frac{\left(1+\psi_{e}\right)(1-u)}{b(u)} \frac{\psi_{e}}{1+\psi_{e}} w(u)\right] .
\end{aligned}
$$

The derivative of $\Sigma_{u}$ with respect to $y_{e}$ is

$$
\frac{\partial \Sigma_{u}\left(u, y_{e}\right)}{\partial y_{e}}=-\frac{1+\psi_{u}}{b(u)^{2}}\left[1+\psi_{e}-\frac{4(1-u) \psi_{e}}{b(u)}\right]\left[1+\frac{\partial S^{*}\left(u, y_{e}\right)}{\partial y_{e}}\right] \gamma
$$

where

$$
\begin{aligned}
\frac{\partial S^{*}\left(u, y_{e}\right)}{\partial y_{e}}= & \frac{\alpha(r-c)}{r}\left\{\frac{(1-u)\left(1+\psi_{e}\right)}{b(u)}\left[1-\frac{2 \psi_{e}}{1+\psi_{e}} \frac{1-u}{b(u)}\right]\right. \\
& \left.\times \gamma\left(\frac{\partial S^{*}\left(u, y_{e}\right)}{\partial y_{e}}+1\right)\right\} .
\end{aligned}
$$

After substituting (C2) into (C1), we obtain

$$
\frac{\partial \Sigma_{u}\left(u, y_{e}\right)}{\partial y_{e}}=\frac{-\frac{1+\psi_{u}}{b(u)^{2}}\left[1+\psi_{e}-\frac{4(1-u) \psi_{e}}{b(u)}\right] \gamma}{1-\frac{1-u}{b(u)}\left[1+\psi_{e}-\frac{2(1-u) \psi_{e}}{b(u)}\right] \frac{\alpha(r-c)}{r} \gamma} .
$$

Letting $\phi(u)$ denote the right-hand side of (C3), we can write $\Sigma_{u}\left(u, y_{e}\right)$ as

$$
\Sigma_{u}\left(u, y_{e}\right)=\Sigma_{u}\left(u, y_{u}\right)+\phi(u)\left(y_{e}-y_{u}\right) .
$$

For any $u \in[\underline{u}, \bar{u}], \Sigma_{u}\left(u, y_{u}\right)$ is finite and $\phi(u)$ is strictly negative. Therefore, there exists a $\bar{y}_{e}(u) \geq y_{u}$ such that $\Sigma_{u}\left(u, y_{e}\right)<0$ for all $y_{e} \in\left[y_{u}, \bar{y}_{e}(u)\right)$ and $\Sigma_{u}\left(u, y_{e}\right)<0$ for all $y_{e}>\bar{y}_{e}(u)$. Since $\partial S^{*}\left(u, y_{e}\right) / \partial u$ has the same sign as $\Sigma_{u}\left(u, y_{e}\right)$, this completes 
the proof of part i. The proof of part ii is similar, and it is omitted for the sake of brevity. QED

Proof of part iii: Suppose $S^{* \prime}(u)<0$ for some $u \in[\underline{u}, \bar{u}]$. In this case, there exist $u_{0}$ and $u_{1}$ such that $\underline{u}<u_{0}<u_{1}<\bar{u}$ and $J_{0}>J_{1}$, where $J_{0} \equiv(1-\gamma)\left[S^{*}\left(u_{0}\right)+y_{e}-\right.$ $\left.y_{u}\right] /(\rho+\delta)$ and $J_{1} \equiv(1-\gamma)\left[S^{*}\left(u_{1}\right)+y_{e}-y_{u}\right] /(\rho+\delta)$. In what follows, we will find a vacancy cost $k$ and a matching function $M$ such that $\left(u_{0}, J_{0}\right)$ and $\left(u_{1}, J_{1}\right)$ are steady states.

Define $x_{0}$ as $\left(1-u_{0}\right) \delta / u_{0}$ and $x_{1}$ as $\left(1-u_{1}\right) \delta / u_{1}$. From the inequalities $\underline{u}<$ $u_{0}<u_{1}<\bar{u}$, it follows that $0<x_{1}<x_{0}<1$. Choose the vacancy cost $k$ to be equal to $J_{1}-\epsilon$, where $\epsilon>0$ and $\epsilon<\min \left\{x\left(J_{0}-J_{1}\right) /\left(x_{0}-x_{1}\right), J_{1}\right\}$. Such a choice for $\epsilon$ is always possible because $J_{0}>J_{1}, x_{0}>x_{1}$, and $J_{1}>0$. Choose the inverse of the jobfinding probability, $\varphi(x) \equiv \lambda^{-1}(x)$, to be such that $\varphi(0)=0$ and

$$
\varphi^{\prime}(x)= \begin{cases}1+2 \gamma_{0} x & \text { if } x \in\left[0, x_{1}\right] \\ 1+2 \gamma_{0} x_{1}+2 \gamma_{1}\left(x-x_{1}\right) & \text { if } x \in\left[x_{1}, x_{0}\right] \\ 1+2 \gamma_{0} x_{1}+2 \gamma_{1}\left(x_{0}-x_{1}\right)+\frac{x-x_{0}}{\left(1-x_{0}\right)(1-x)} & \text { if } x \in\left[x_{0}, 1\right],\end{cases}
$$

where the parameters $\gamma_{0}$ and $\gamma_{1}$ are

$$
\begin{gathered}
\gamma_{0}=\frac{J_{1}-k}{k x_{1}}, \\
\gamma_{1}=\frac{x_{0} J_{0}-x_{1} J_{1}}{k\left(x_{0}-x_{1}\right)^{2}}-\frac{1+2 \gamma_{0} x_{1}}{x_{0}-x_{1}} .
\end{gathered}
$$

First, notice that $\varphi(x)$ is strictly increasing and strictly convex for all $x \in[0,1]$. In fact, $k<J_{1}$ implies $\gamma_{0}>0$ and $k>J_{1}-x_{0}\left(J_{0}-J_{1}\right) /\left(x_{0}-x_{1}\right)$ implies $\gamma_{1}>0$. In turn, $\gamma_{0}>0$ and $\gamma_{1}>0$ imply that $\varphi^{\prime}(x)$ is strictly positive and strictly increasing for all $x \in[0,1]$. Second, notice that $\varphi(x)$ is such that $\varphi(0)=0$ and $\varphi(1)=\infty$. Third, $\varphi(x)$ is such that

$$
\begin{aligned}
& \varphi\left(x_{1}\right)=\varphi(0)+\int_{0}^{x_{1}}\left(1+2 \gamma_{0} x\right) d x=\frac{J_{1} x_{1}}{k}, \\
& \varphi\left(x_{2}\right)=\varphi\left(x_{1}\right)+\int_{x_{1}}^{x_{0}}\left[1+2 \gamma_{0} x_{1}+2 \gamma_{1}\left(x-x_{1}\right)\right] d x=\frac{J_{0} x_{0}}{k} .
\end{aligned}
$$

From the properties of $\varphi(x)$, it follows that the job-finding probability function $\lambda(\theta)$ is strictly increasing, strictly concave, and such that $\lambda(0)=0, \lambda(\infty)=1$, and $\lambda^{\prime}(0)=1$. In turn, from the properties of $\lambda(\theta)$, it follows that the job-filling probability function $\eta(\theta) \equiv \lambda(\theta) / \theta$ is strictly decreasing and such that $\eta(0)=1$ and $\eta(\infty)=0$. Therefore, the function $\varphi(x)$ defined in (C5) implies a matching process $\lambda(\theta), \eta(\theta), M(u, v)=u \lambda(u / v)$ that satisfies all of the regularity assumptions made in Section II. Moreover, since $\epsilon<J_{1}, k=J_{1}-\epsilon>0$. Therefore, the vacancy cost $k$ the assumptions made in Section II.

Now, notice that both $\left(u_{0}, J_{0}\right)$ and $\left(u_{1}, J_{1}\right)$ satisfy the stationarity conditions (14) and (15) and, hence, both $\left(u_{0}, J_{0}\right)$ and $\left(u_{1}, J_{1}\right)$ are steady states. In fact, the definition of $J_{0}$ implies that 


$$
J_{0}=\frac{(1-\gamma)\left[S^{*}\left(u_{0}\right)+y_{e}-y_{u}\right]}{\rho+\delta},
$$

and the first line in (C6) implies that

$$
\begin{aligned}
\frac{x_{0}}{\varphi\left(x_{0}\right)} & =\frac{k}{J_{0}} \Leftrightarrow \frac{\lambda\left(\varphi\left(x_{0}\right)\right)}{\varphi\left(x_{0}\right)}=\frac{k}{J_{0}} \\
& \Leftrightarrow x_{0}=\lambda\left(\eta^{-1}\left(\frac{k}{J_{0}}\right)\right) \\
& \Leftrightarrow u_{0}=\frac{\delta}{\delta+\lambda\left(\theta\left(J_{0}\right)\right)} .
\end{aligned}
$$

Similarly, the definition of $J_{1}$ and the second line in (C6) imply that

$$
\begin{aligned}
& J_{1}=\frac{(1-\gamma)\left[S^{*}\left(u_{1}\right)+y_{e}-y_{u}\right]}{\rho+\delta}, \\
& u_{1}=\frac{\delta}{\delta+\lambda\left(\theta\left(J_{1}\right)\right)} .
\end{aligned}
$$

Now, suppose $S^{* \prime}(u) \geq 0$ for all $u \in[\underline{u}, \bar{u}]$. On the way to a contradiction, suppose that there exist two steady states $\left(u_{0}, J_{0}\right)$ and $\left(u_{1}, J_{1}\right)$. From the stationarity condition (15) and the fact that $S^{* \prime}(u) \geq 0$ for all $u \in[\underline{u}, \bar{u}]$, it follows that

$$
J_{0}=\frac{(1-\gamma)\left[S^{*}\left(u_{0}\right)+y_{e}-y_{u}\right]}{\rho+\delta} \leq \frac{(1-\gamma)\left[S^{*}\left(u_{0}\right)+y_{e}-y_{u}\right]}{\rho+\delta}=J_{1} .
$$

From the stationarity condition (14), it follows that

$$
u_{0}=\frac{\delta}{\delta+\lambda\left(\theta\left(J_{0}\right)\right)}<\frac{\delta}{\delta+\lambda\left(\theta\left(J_{1}\right)\right)}=u_{1} .
$$

Since $J_{0} \leq J_{1}, \lambda(\theta)$ is increasing in $\theta$ and $\theta(J)$ is increasing in $J, \lambda\left(\theta\left(J_{0}\right)\right) \leq \lambda\left(\theta\left(J_{1}\right)\right)$, which contradicts the inequality in (C8). QED

\section{Appendix D}

\section{Global Dynamics}

In this appendix, we provide a complete characterization of the set of perfect foresight equilibria of the model. We carry out the analysis under the assumption that the dynamical system (12)-(13) admits exactly three steady states, $E_{1}, E_{2}$, and $E_{3}$. It is straightforward to verify that the steady state with the lowest unemployment rate, $E_{1}$, is a saddle. Similarly, the steady state with the highest unemployment rate, $E_{3}$, is a saddle. In contrast, the intermediate steady state, $E_{2}$, is a sink or a source depending on whether the unemployment rate is greater or smaller than $\delta /(\delta+\rho)$. Here, we assume that $E_{2}$ is a sink, as this is the relevant case for most reasonable parameterizations of the model. Moreover, for the sake of exposition, we assume that the $J$-nullcline is quasi-convex. When the $J$ - 


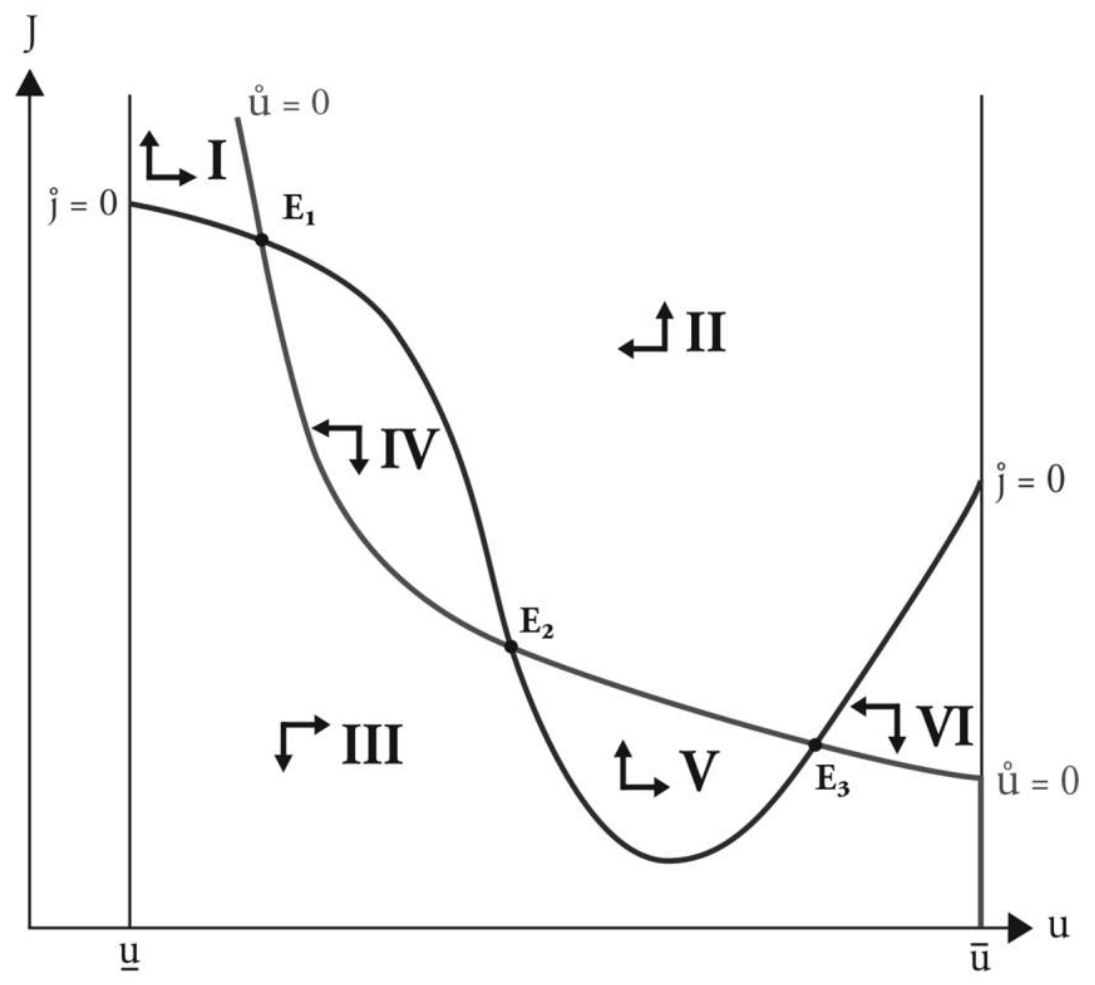

FIG. D1.-Direction of motion. Color version available as an online enhancement.

nullcline is not quasi-convex, the analysis is slightly different, but the qualitative features of the set of equilibria are unchanged.

In figure D1, we plot the $u$-nullcline, the $J$-nullcline, and the direction of motion of the solutions to the dynamical system (12)-(13) in the six regions defined by the intersections of the two nullclines. Using the direction of motion of the solutions to (12)-(13) and using the fact that any solution to (12)-(13) must cross the $u$-nullcline vertically and the $J$-nullcline horizontally, we can characterize the shape of the stable manifold $J_{1}^{S}$ associated with the steady state $E_{1}$ and of the stable manifold $J_{3}^{S}$ associated with the steady state $E_{3}$. In particular, it is straightforward to verify that the left backward extension of the stable manifold $J_{1}^{S}$ to the left of $E_{1}$ must go through region III and exit the domain at $\underline{u}$. The backward extension of $J_{1}^{S}$ to the right of $E_{1}$ must go through region II and then it may either (i) exit the domain at $\bar{u}$; (ii) go through regions V and III and exit the domain at $\bar{u}$; or (iii) circle around the regions V, III, IV, and II without ever exiting the domain. ${ }^{15}$ Similarly, the backward extension of the stable manifold $J_{3}^{S}$

${ }^{15}$ For the sake of brevity, the analysis abstracts from the knife-edge cases in which the stable manifolds are either homoclinic - i.e., the backward extension of the stable mani- 
A

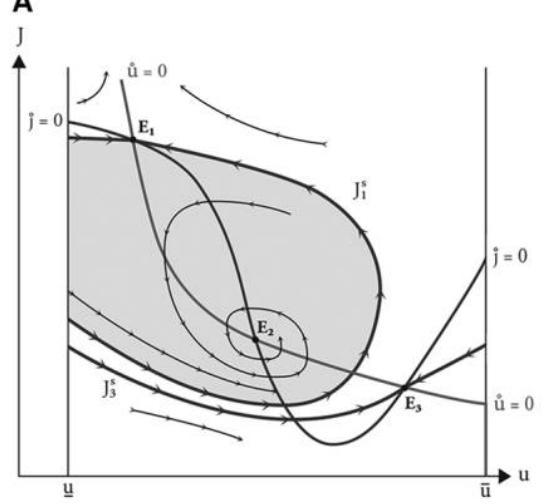

C

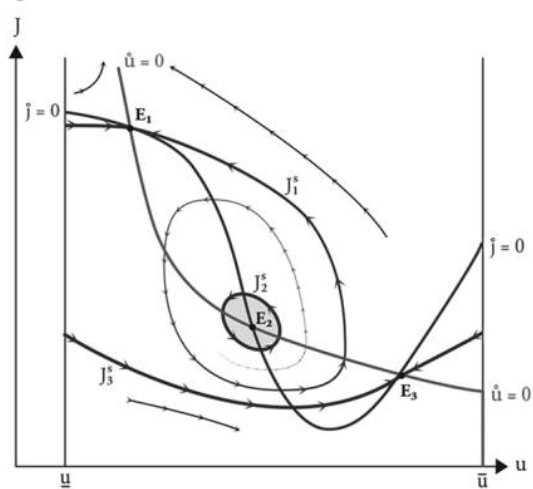

B

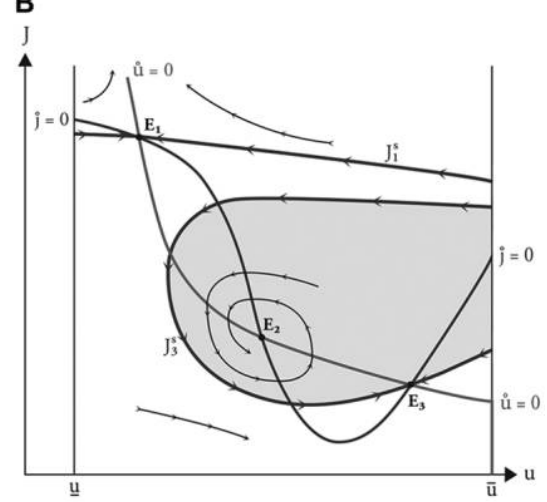

D

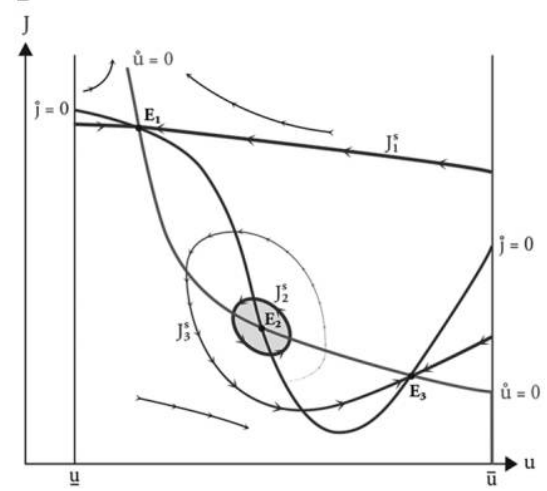

FIG. D2.-Perfect foresight equilibria. Color version available as an online enhancement.

to the right of $E_{3}$ must go through region VI and exit the domain at $\bar{u}$. The backward extension of $J_{3}^{S}$ to the left of $E_{3}$ goes through region $V$ and then it may either (i) exit the domain at $\underline{u}$; (ii) go through regions III, IV, and II and exit the domain at $\bar{u}$; or (iii) circle around the regions III, IV, II, and V without ever exiting the domain. After eliminating incompatible cases, the above classification leaves us with five possible scenarios.

In the main text, we have already analyzed the case in which the right branch of $J_{1}^{S}$ exits at $\bar{u}$ and the left branch of $J_{3}^{S}$ exits at $u$. Figure D2A plots the solution to the dynamical system (12)-(13) when both the right branch of $J_{1}^{S}$ and the left branch of $J_{3}^{S}$ exit at $\underline{u}$. Let $\bar{u}_{1}$ denote the easternmost point on the stable manifold associated with $E_{1}$. For any initial unemployment $u_{0} \in\left[\underline{u}, \bar{u}_{1}\right]$, there are three types of equilibria. In particular, there are two equilibria along the stable manifold converging to $E_{1}$ (one starting on the upper branch of $J_{1}^{S}$ and one start-

fold associated with one saddle steady state converges to the same steady state-or heteroclinic - i.e., the backward extension of the stable manifold associated with one saddle steady state converges to the other saddle steady state. 
ing on the lower branch of $J_{1}^{S}$ ), there is one equilibrium along the stable manifold converging to $E_{3}$, and there is a continuum of equilibria starting between the upper and the lower branches of $J_{1}^{S}$ and converging to either $E_{2}$ or a limit cycle around $E_{2}$. For any initial unemployment $u_{0} \in\left(\bar{u}_{1}, \bar{u}\right]$, the only equilibrium is the stable manifold converging to $E_{3}$. Figure D2B illustrates a case that is symmetric to the one in figure $\mathrm{D} 2 A$.

Figure D2C plots the solution to the dynamical system (12)-(13) when the right branch of $J_{1}^{S}$ coils around $E_{2}$, while the left branch of $J_{3}^{S}$ exits at $\underline{u}$. In this case, one can prove that there exists a repellent limit cycle around $E_{2}$ (see Boldrin, Kiyotaki, and Wright 1993, proposition 5). Let $J_{2}^{C}$ denote the limit cycle. Moreover, let $\underline{u}_{1}$ and $\bar{u}_{1}$ be the westernmost and easternmost points on the stable manifold $J_{1}^{S}$ and let $\underline{u}_{2}$ and $\bar{u}_{2}$ be the westernmost and easternmost points on the

limit cycle $J_{2}^{C}$. For any initial unemployment $u_{0} \in\left[\underline{u}, u_{2}\right) \cup\left(\bar{u}_{2}, \bar{u}_{1}\right]$, there are two types of equilibria: the stable manifold converging to $E_{1}$ and the stable manifold converging to $E_{3}$. For any initial unemployment $u_{0} \in\left[u_{2}, \bar{u}_{2}\right]$, there are two additional types of equilibria: the limit cycle and a continuum of equilibria starting inside the limit cycle and converging to $E_{2}$. For any initial unemployment $u_{0} \in\left(\bar{u}_{1}, \bar{u}\right]$, the only equilibrium is the stable manifold converging to $E_{3}$. Figure $\mathrm{D} 2 D$ illustrates a case that is symmetric to the one in figure $\mathrm{D} 2 C$.

\section{Appendix E}

\section{Robustness}

In Section IV, we showed that a reasonably calibrated version of the model admits multiple steady states and multiple perfect foresight equilibria. In this appendix, we want to understand whether the existence of multiple steady states and multiple equilibria is robust to alternative choices of calibration targets-especially those describing the shopping behavior of employed and unemployed buyers - and parameter values - especially those describing the product market.

Panel A of table E1 reports the steady-state unemployment rates as we let the target for the relative expenditures of unemployed buyers vary between 70 and 90 percent of the expenditures of employed buyers (horizontal axis) and the target for the relative time spent shopping by unemployed buyers vary between 110 and 140 percent of the time spent shopping by employed buyers (vertical axis), while keeping the product market parameters $\alpha, \psi_{e}$, and $R$ constant and recalibrating all the other parameters so as to match their respective empirical targets. We choose not to recalibrate the product market parameters because they are not precisely pinned down by the associated empirical targets, in the sense that the calibrated value of the product market parameters changes quite dramatically in response to relatively small changes in the value of the other parameters of the model.

Panel A of table E1 shows that, for all alternative calibrations, the model admits three steady states. The unemployment rate at the first steady state is pinned down by the calibration targets for the workers' transition rates between employment and unemployment and, hence, does not vary. The unemployment rate at the intermediate steady state is decreasing in the relative shopping time of un- 
TABLE E1

Robustness: Steady-State Unemployment Rates and Price Statistics for Combinations of Targets for Expenditure Ratio and Shopping Time Ratio of Unemployed to EMPloyed

\begin{tabular}{|c|c|c|c|c|}
\hline \multirow{2}{*}{$\begin{array}{l}\text { Shopping Time } \\
\text { Ratio }\end{array}$} & \multicolumn{4}{|c|}{ UNEMPLOYED-EMPLOYED EXPENDITURE RATIO } \\
\hline & .75 & .8 & .85 & .9 \\
\hline & \multicolumn{4}{|c|}{ A. Steady-State Unemployment Rates } \\
\hline 1.1 & $5.3,13.4,100$ & $5.3,13.9,100$ & $5.3,14.5,100$ & $5.3,15.5,100$ \\
\hline 1.2 & $5.3,9.8,100$ & $5.3,9.7,100$ & $5.3,9.5,100$ & $5.3,9.3,96.9$ \\
\hline 1.3 & $5.3,8.0,100$ & $5.3,7.7,100$ & $5.3,7.4,100$ & $5.3,7.1,94.5$ \\
\hline \multirow[t]{2}{*}{1.4} & $5.3,6.9,100$ & $5.3,6.6,100$ & $5.3,6.3,100$ & $5.3,6.0,92.6$ \\
\hline & \multicolumn{4}{|c|}{ B. Price Statistics } \\
\hline 1.1 & $.18,1.56, .99$ & $.19,1.57, .99$ & $.19,1.57, .99$ & $.21,1.58, .99$ \\
\hline 1.2 & $.27,1.65, .99$ & $.28,1.66, .99$ & $.3,1.67, .99$ & $.33,1.68, .99$ \\
\hline 1.3 & $.4,1.74, .98$ & $.42,1.75, .98$ & $.46,1.77, .98$ & $.51,1.79, .98$ \\
\hline 1.4 & $.58,1.82, .97$ & $.62,1.84, .97$ & $.67,1.87, .97$ & $.75,1.89, .97$ \\
\hline
\end{tabular}

Note.-In panel B, the numbers in each cell refer to the coefficient of variation of prices, the ratio of the maximum price to minimum price, and the price paid by unemployed relative to employed.

employed buyers and increasing in the relative expenditures of unemployed buyers. These results are intuitive because, whenever we increase the difference in shopping behavior of unemployed and employed buyers (on either the expenditure or the shopping time dimension), the seller's revenues become more sensitive to the unemployment rate, the $J$-nullcline becomes steeper, and the unemployment rate at the intermediate steady state falls. Note that, for all alternative calibrations, the unemployment rate at the intermediate steady state is between 5.5 and 11 percent, values that are lower than $\delta /(\delta+\rho) \sim 0.9$. Therefore, the intermediate steady state is always a sink, and in light of Appendix D, the model admits multiple equilibria.

Since we do not recalibrate the product market parameters $\alpha, \psi_{e}$, and $R$, it is useful to report the values of the associated calibration targets: the standard deviation of prices, the ratio of the highest to the lowest price, and the relative price paid by unemployed workers (see panel B of table E1). For most calibrations, the extent of price dispersion generated by the model is broadly consistent with the empirical evidence in Kaplan and Menzio (2015), once we consider the fact that some of the empirical price dispersion may be due to factors that are not accounted for in our model (measurement error, store quality, etc.).

Panel A of table E2 reports the steady-state unemployment rates as we let $\alpha$ vary between 0.8 and 1 (vertical axis) and $R$ vary between 10 and 20 (horizontal axis), while keeping $\psi_{e}$ constant and recalibrating all the other parameters so as to match their respective empirical targets. For all alternative calibrations, we find that the model admits three steady states. Again, the unemployment rate at the first steady state is pinned down by the calibration targets for the workers' transition rates and, hence, it does not vary. The unemployment rate at the second steady state is decreasing in $\alpha$ and $R$. This finding is intuitive, since increas- 
TABLE E2

Robustness: Steady-State Unemployment Rates and Price STATISTICS FOR COMBinations OF $\alpha$ AND $R$

\begin{tabular}{|c|c|c|c|c|}
\hline \multirow{2}{*}{$\begin{array}{l}\text { WEIGHT ON BJ } \\
\text { GoODS }(\alpha)\end{array}$} & \multicolumn{4}{|c|}{ Home Production Technology for BJ Goods $(R)$} \\
\hline & 10.00 & 13.33 & 16.67 & 20.00 \\
\hline & \multicolumn{4}{|c|}{ A. Steady-State Unemployment Rates } \\
\hline .80 & $5.3,13.9,100$ & $5.3,13.2,100$ & $5.3,12.8,100$ & $5.3,12.5,100$ \\
\hline .87 & $5.3,11.9,100$ & $5.3,11.3,100$ & $5.3,10.9,100$ & $5.3,10.7,100$ \\
\hline .93 & $5.3,10.2,100$ & $5.3,9.7,100$ & $5.3,9.3,100$ & $5.3,9.1,100$ \\
\hline \multirow[t]{2}{*}{1.00} & $5.3,8.8,100$ & $5.3,8.3,100$ & $5.3,8.0,100$ & $5.3,7.8,100$ \\
\hline & \multicolumn{4}{|c|}{ B. Price Statistics } \\
\hline .80 & $.23,1.2, .99$ & $.31,1.35, .99$ & $.4,1.5, .98$ & $.49,1.65, .98$ \\
\hline .87 & $.24,1.3, .99$ & $.33,1.47, .98$ & $.42,1.63, .98$ & $.51,1.79, .98$ \\
\hline .93 & $.25,1.4, .99$ & $.34,1.58, .98$ & $.43,1.75, .98$ & $.53,1.93, .98$ \\
\hline 1.00 & $.26,1.5, .99$ & $.36,1.69, .98$ & $.45,1.88, .98$ & $.54,2.07, .98$ \\
\hline
\end{tabular}

NoTE.- In panel B, the numbers in each cell refer to the coefficient of variation of prices, the ratio of the maximum price to minimum price, and the price paid by unemployed relative to employed.

ing either $\alpha$ or $R$ makes the seller's revenues more sensitive to unemployment, makes the $J$-nullcline steeper, and, hence, lowers the unemployment rate at the second steady state. Over the entire parameter range, the unemployment rate at the second steady state goes from a minimum of 8 percent to a maximum of 14 percent, values that are all lower than $\delta /(\delta+\rho)$. Hence, over the entire parameter range, the second steady state is a sink and the model admits multiple equilibria. Panel B of table E2 shows that both measures of price dispersion in-

TABLE E3

Robustness: Steady-State Unemployment Rates and Price Statistics For Combinations of Targets for Elasticity of UE Rate with Respect to $\theta$ and Firms' Profit Margin

\begin{tabular}{|c|c|c|c|c|}
\hline \multirow[b]{2}{*}{ UE Elasticity } & \multicolumn{4}{|c|}{ Firms' Profit MARgin } \\
\hline & .05 & .10 & .15 & .20 \\
\hline & \multicolumn{4}{|c|}{ A. Steady-State Unemployment Rates } \\
\hline .45 & $5.3,20.7,70.3$ & 5.3 & 5.3 & 5.3 \\
\hline .55 & $5.3,12.6,92.4$ & $5.3,23.1,78.1$ & $5.3,48.8,100$ & 5.3 \\
\hline .65 & $5.3,8.3,100$ & $5.3,13.2,100$ & $5.3,18.8,94.9$ & $5.3,25.9,85.6$ \\
\hline \multirow[t]{2}{*}{.75} & $5.3,5.7,100$ & $5.3,8.2,100$ & $5.3,10.7,100$ & $5.3,13.4,100$ \\
\hline & \multicolumn{4}{|c|}{ B. Price Statistics } \\
\hline .45 & $.37,1.72, .98$ & $.41,1.72, .98$ & $.44,1.72, .98$ & $.48,1.72, .98$ \\
\hline .55 & $.37,1.72, .98$ & $.41,1.72, .98$ & $.44,1.72, .98$ & $.48,1.72, .98$ \\
\hline .65 & $.37,1.72, .98$ & $.41,1.72, .98$ & $.44,1.72, .98$ & $.48,1.72, .98$ \\
\hline .75 & $.37,1.72, .98$ & $.41,1.72, .98$ & $.44,1.72, .98$ & $.48,1.72, .98$ \\
\hline
\end{tabular}

NoTE.- In panel B, the numbers in each cell refer to the coefficient of variation of prices, the ratio of the maximum price to minimum price, and the price paid by unemployed relative to employed. 
crease with $R$ and $\alpha$, while the relative price paid by unemployed buyers hardly changes.

Finally, table E3 reports the steady-state unemployment rates as we vary the target for the elasticity of the UE rate with respect to labor market tightness from 0.45 to 0.75 (vertical axis) and the firm's profit margin from 5 to 20 percent (horizontal axis), while keeping the parameters $\alpha, \psi_{e}$, and $R$ constant and recalibrating all the remaining parameters. We find that, in the region where the elasticity of the UE rate is relatively high or the profit margin is relatively low, the model admits three steady states. In this region, the unemployment rate associated with the intermediate steady state is decreasing in the elasticity of UE and increasing in the firm's profit margin. These findings are intuitive because the $u$-nullcline becomes more curved as we increase the elasticity of the UE rate, and the J-nullcline becomes steeper as we lower the profit margin. It is only in the region where the elasticity of the UE rate is relatively low and the profit margin of the firm is relatively high that the model has a unique steady state. Moreover, we find that this region shrinks when we increase the targeted difference in either expenditures or shopping time between employed and unemployed workers.

\section{References}

Aguiar, M., and E. Hurst. 2007. "Life-Cycle Prices and Production." A.E.R. 97:1533-59.

Angeletos, M., and J. La'O. 2013. “Sentiments.” Econometrica 81:739-79.

Benhabib, J., and R. Farmer. 1994. "Indeterminacy and Increasing Returns." I. Econ. Theory 63:19-41.

Benhabib, J., P. Wang., and Y. Wen. 2012. "Sentiments and Aggregate Fluctuations." Manuscript, New York Univ.

Bentolila, S., and A. Ichino. 2008. "Unemployment and Consumption Near and Far Away from the Mediterranean.” I. Population Econ. 21:255-80.

Bilbiie, F., F. Ghironi, and M. Melitz. 2012. "Endogenous Entry, Product Variety, and Business Cycles." L.P.E. 120:304-45.

Boldrin, M., N. Kiyotaki, and R. Wright. 1993. "A Dynamic Equilibrium Model of Search, Production, and Exchange." L.Econ. Dvnamics and Control 17:72358.

Burdett, K., and K. Judd. 1983. "Equilibrium Price Dispersion." Econometrica 51:955-70.

Christiano, L., and S. Harrison. 1999. "Chaos, Sunspots and Automatic Stabilizers." I. Monetarv Econ. 44:3-31.

Cooper, R., and A. John. 1988. "Coordinating Coordination Failures in Keynesian Models.” O.J.E. 103:441-63.

Diamond, P. 1982. "Aggregate Demand Management in Search Equilibrium." L.P.E. 90:881-94.

Diamond, P., and D. Fudenberg. 1989. "Rational Expectations Business Cycles in Search Equilibrium." L.P.E. 97:606-19.

Farmer, R. 2012a. "Confidence, Crashes and Animal Spirits." Econ. J. 122:15572.

. 2012b. "The Stock Market Crash of 2008 Caused the Great Recession: Theory and Evidence." L. Econ. Dvnamics and Control 36:693-707. 
Farmer, R., and J. Guo. 1994. "Real Business Cycles and the Animal Spirits Hypothesis." L. Econ. Theory 63:42-72.

Head, A., L. Liu, G. Menzio, and R. Wright. 2012. "Sticky Prices: A New Monetarist Approach." L. European Econ. Assoc. 10:939-73.

Heller, W. 1986. "Coordination Failure under Complete Markets with Applications to Effective Demand." In Equilibrium Analvsis: Essavs in Honor of Kenneth L. Arrow, vol. 2, edited by Walter P. Heller, Ross M. Starr, and David A. Starrett, 155-75. Cambridge: Cambridge Univ. Press.

Howitt, P., and P. McAfee. 1992. "Animal Spirits." A.E.R. 82:493-507.

Kaplan, G., and G. Menzio. 2013. "Shopping Externalities and Self-Fulfilling Unemployment Fluctuations." Working Paper no. 18777, NBER, Cambridge, MA.

_ 2015. "The Morphology of Price Dispersion." Internat. Econ. Rev. 56: $1165-1206$.

Krueger, A., and A. Mueller. 2010. "Job Search and Unemployment Insurance: New Evidence from Time Use Data." L. Public Econ. 94:298-307.

Menzio, G., and S. Shi. 2011. "Efficient Search on the Job and the Business Cycle." I.P.E. 119:468-510.

Mortensen, D. 1999. "Equilibrium Unemployment Dynamics." Internat. Econ. Rev. 40:889-914.

Mortensen, D., and C. Pissarides. 1994. "Job Creation and Job Destruction in the Theory of Unemployment." Rev. Econ. Studies 61:397-415.

Petrongolo, B., and C. Pissarides. 2001. "Looking into the Black Box: A Survey of the Matching Function." L.Econ. Literature 39:390-431.

Pissarides, C. 1985. "Short-Run Equilibrium Dynamics of Unemployment, Vacancies, and Real Wages." A.E.R. 75:676-90.

. 2009. "The Unemployment Volatility Puzzle: Is Wage Stickiness the Answer?" Econometrica 77:1339-69.

Roberts, J. 1987. "An Equilibrium Model with Involuntary Unemployment at Flexible, Competitive Prices and Wages.” A.E.R. 77:856-74.

Shimer, R. 2005. "The Cyclical Behavior of Unemployment and Vacancies." A.E.R. 95:25-49.

Stephens, M. 2001. "The Long-Run Consumption Effects of Earnings Shocks." Rev. Econ. and Statis. 83:28-36.

2004. "Job Loss Expectations, Realizations, and Household Consumption Behavior." Rev. Econ. and Statis. 86:253-69. 